Purdue University

Purdue e-Pubs

CTRC Research Publications

Cooling Technologies Research Center

2009

\title{
The Influence of Surface Roughness on Nucleate Pool Boiling Heat Transfer
}

B. J.Jones

Purdue University

J.P.McHale

Purdue University

S V. Garimella

Purdue University, sureshg@purdue.edu

Follow this and additional works at: http://docs.lib.purdue.edu/coolingpubs

Jones, B. J.; McHale, J. P.; and Garimella, S V., "The Influence of Surface Roughness on Nucleate Pool Boiling Heat Transfer" (2009). CTRC Research Publications. Paper 253.

http://dx.doi.org/DOI: 10.1115/1.3220144

This document has been made available through Purdue e-Pubs, a service of the Purdue University Libraries. Please contact epubs@purdue.edu for additional information. 


\section{The Influence of Surface Roughness on Nucleate Pool Boiling Heat Transfer}

\section{Benjamin J. Jones} John P. McHale

\section{Suresh V. Garimella ${ }^{1}$}

e-mail: sureshg@purdue.edu

\author{
NSF Cooling Technologies Research Center, \\ School of Mechanical Engineering, \\ and Birck Nanotechnology Center, \\ Purdue University, \\ 585 Purdue Mall, \\ West Lafayette, IN 47907-2088
}

The effect of surface roughness on pool boiling heat transfer is experimentally explored over a wide range of roughness values in water and Fluorinert ${ }^{\mathrm{TM}}$ FC-77, two fluids with different thermal properties and wetting characteristics. The test surfaces ranged from a polished surface $\left(R_{a}\right.$ between $0.027 \mu \mathrm{m}$ and $\left.0.038 \mu \mathrm{m}\right)$ to electrical discharge machined $(E D M)$ surfaces with a roughness $\left(R_{a}\right)$ ranging from $1.08 \mu \mathrm{m}$ to $10.0 \mu \mathrm{m}$. Different trends were observed in the heat transfer coefficient with respect to the surface roughness between the two fluids on the same set of surfaces. For FC-77, the heat transfer coefficient was found to continually increase with increasing roughness. For water, on the other hand, EDM surfaces of intermediate roughness displayed similar heat transfer coefficients that were higher than for the polished surface, while the roughest surface showed the highest heat transfer coefficients. The heat transfer coefficients were more strongly influenced by surface roughness with FC-77 than with water. For FC-77, the roughest surface produced $210 \%$ higher heat transfer coefficients than the polished surface while for water, a more modest $100 \%$ enhancement was measured between the same set of surfaces. Although the results highlight the inadequacy of characterizing nucleate pool boiling data using $R_{a}$, the observed effect of roughness was correlated using $h \propto R_{a}^{m}$ as has been done in several prior studies. The experimental results were compared with predictions from several widely used correlations in the literature.

[DOI: $10.1115 / 1.3220144]$

Keywords: nucleate pool boiling, heat transfer, surface roughness

\section{Introduction}

Surface roughness has long been known to have a significant impact on the boiling process. In 1936, Jakob [1] reported that both surface roughness and the level of corrosion and oxidation of the surface dramatically influence the boiling curve. At the time, the bubble incipience process was not well understood. By the late 1950 s, one of the prevailing theories was that bubbles emanate from cavities containing entrapped vapor [2]. The experiments by Clark et al. [3] provided strong evidence for the theory that bubbles do indeed emanate from cavities and other surface imperfections. The theoretical analysis by Bankoff [4] further substantiated the vapor entrapment theory by showing that only unwetted cavities can serve as nucleation sites, and that only cavities of a certain shape can serve as vapor traps [5]. The role of cavities was further elucidated by Griffith and Wallis [6], who showed that the cavity radius determines the superheat required for bubble nucleation in a uniformly superheated liquid, with larger cavities requiring lower wall superheats. Hsu [7] extended this analysis to include the effects of the thermal boundary layer and showed that only a certain range of cavity sizes can serve as active nucleation sites.

The realization of the importance of cavities spurred interest in using roughened surfaces as a means of increasing the number of nucleation sites and size of cavities, thus enhancing boiling heat transfer. Several investigations into the effect of surface roughness were carried out in the 1950s and 1960s. Corty and Foust [8] investigated a variety of copper and nickel surfaces prepared with different levels of polishing. They found that the surface roughness not only affected the superheat required for incipience but also the slope of the boiling curve. Rougher surfaces resulted in

${ }^{1}$ Corresponding author.

Manuscript received April 15, 2008; final manuscript received May 6, 2009; published online October 15, 2009. Review conducted by Yogesh Jaluria. lower superheats for a given heat flux, which was attributed to the presence of larger unwetted cavities on the rougher surfaces. Similar conclusions were reached by other researchers: Kurihara and Myers [9], who studied a variety of fluids boiling from copper surfaces with differing levels of polish; Hsu and Schmidt [10], who studied the boiling of water from stainless steel surfaces; and Marto and Rohsenow [11] who studied the boiling of sodium from surfaces prepared using a variety of different techniques. Berenson [12] studied the boiling of $n$-pentane on surfaces of varying roughness and found large variations in the heat transfer coefficient, of up to $600 \%$, due to the differences in surface characteristics.

The increased understanding of the role of surface condition has also led to commercially available enhanced surfaces for improved boiling performance. Many of these boiling enhancements are designed to create re-entrant-type cavity structures which are more difficult for the liquid to fully wet than simple cavity shapes and, based on the analysis of Griffith and Wallis [6], are believed to serve as more stable nucleation sites. Therefore, these enhanced surface geometries typically lead to better boiling performance compared with roughened surfaces produced by conventional machining processes. A wide variety of industrial applications, however, still utilize surfaces produced using conventional machining processes and these surfaces remain the focus of the present work. Good reviews of enhanced boiling surfaces have been provided by Webb $[13,14]$.

For surfaces produced using conventional manufacturing techniques, several researchers have noted the inability of commonly used surface roughness parameters, such as the rms roughness $\left(R_{q}\right)$ or average roughness $\left(R_{a}\right)$, to explain the variation in observed nucleate boiling heat transfer characteristics. Berenson [12] noted that the rms surface roughness itself was not the best indicator of the resulting performance since lapped surfaces had much higher heat transfer coefficients than rougher surfaces produced 
with emery paper. Bier et al. [15] reached a similar conclusion after studying the boiling of R11 and R115 from surfaces prepared using various techniques over a range of pressures. Chowdhury and Winterton [16] suggested that rougher surfaces would yield higher nucleate pool boiling heat transfer coefficients if a consistent method of surface preparation is used, but the results from other investigators have not shown such a trend. Vachon et al. [17] investigated boiling from unidirectionally polished and chemically etched surfaces of varying roughness in water. The results from the polished surfaces indicated that roughening the surfaces only improved the boiling performance up to a certain point. The best heat transfer performance was obtained with an $1 \mu \mathrm{m}$ rms surface roughness, and further roughening of the surface yielded no additional benefit. The results from the chemically etched surfaces were more varied and showed the inadequacy of using rms roughness to characterize boiling surfaces.

Several researchers have also noted an apparent maximum heat transfer coefficient with respect to surface roughness as observed by Vachon et al. [17]. Kravchenko and Ostruovskiy [18] studied various organic fluids and nitrogen boiling from stainless steel tubes. Their results indicated that vertical tubes with a roughness average $\left(R_{a}\right)$ greater than $0.58 \mu \mathrm{m}$ do not experience any further improvement in the heat transfer coefficient. Grigoriev et al. [19] studied the boiling of helium for surfaces of varying roughness and also noted that once a surface was sufficiently rough, additional roughening yielded no benefit. Many other researchers, however, have not observed such an apparent maximum heat transfer coefficient, and this variety of results may simply indicate the inadequacy of correlating nucleate boiling heat transfer data using surface roughness parameters.

Recognizing the deficiencies of characterizing boiling surfaces with surface roughness parameters, several researchers have attempted to characterize the surfaces in a more mechanistic fashion by measuring cavity sizes and shapes using optical or electron microscopy [20-23]. Using an optical microscope, Wang and Dhir $[23,24]$ characterized the cavity structures on polished copper surfaces and developed a wetting criterion for determining the active cavity size distribution. Their theoretical analysis agreed well with experimental results. However, such an approach is only tractable on very smooth surfaces on which the number of cavities is relatively small. Attempts to characterize stochastically rough surfaces have been met with marginal success. Qi et al. [25] and Luke $[26,27]$ have developed methods for determining active cavity size distributions from 3D profilometry data of boiling surfaces. However, the simplistic treatment of the surface structure and the wetting phenomenon used in the analyses has limited the utility of such predictions.

While numerous investigators have reported on the inefficacy of correlating nucleate boiling data using surface roughness parameters, some researchers have reported success in correlating the general trend of increasing heat transfer coefficients with increased roughness. Stephan [28], in his investigation of boiling of R11 from copper surfaces of varying roughness, found that the influence of surface roughness on the heat transfer coefficient at a fixed heat flux could be represented with $h \propto R_{p \text {,old }}^{0.133}$, where $R_{p \text {,old }}$ is the German "Glättungstiefe" defined by DIN 4762/1:1960. Danilova and Bel'skii [29] found a somewhat different dependence of $h \propto R_{z}^{0.2}$ when studying R12 and R113 boiling from tube surfaces prepared using various techniques. Both these studies $[28,29]$ were conducted at low reduced pressure. Nishikawa et al. $[30,31]$ extended the study of roughness to a wide range of reduced pressure and found that the effect of surface roughness on the heat transfer coefficient diminishes as the pressure approaches the critical pressure. They found that the relation $h \propto R_{p \text {,old }}^{0.2\left(1-P_{r}\right)}$ best represented their experimental data.

A relationship of the form $h \propto R^{m}$ does not adequately explain many of the previously discussed anomalies when correlating nucleate pool boiling data using surface roughness parameters. Nonetheless, it does provide a simple framework for incorporating
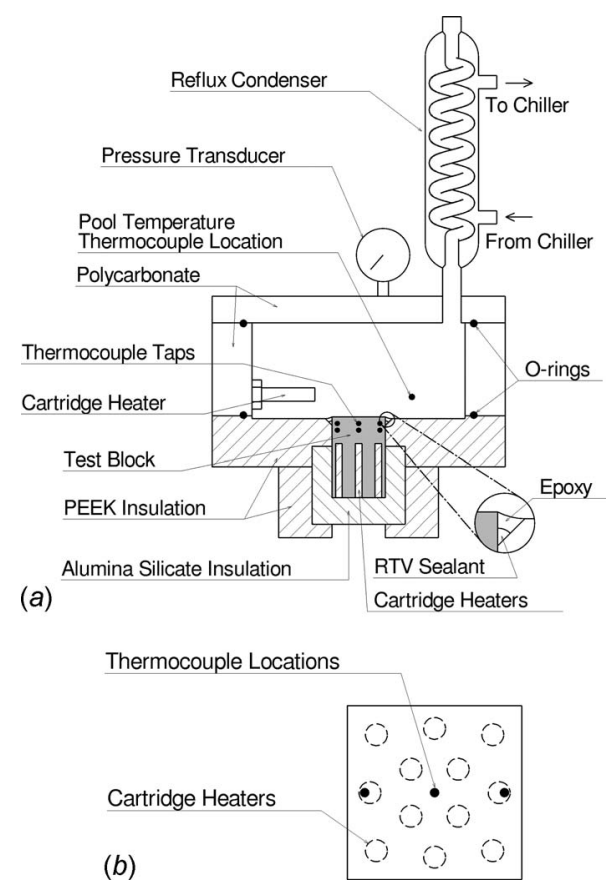

Fig. 1 (a) Schematic of pool boiling facility and (b) top view of test block showing the locations of thermocouples and cartridge heaters

the influence of surface roughness into nucleate pool boiling correlations; and indeed several correlations have accounted for the surface roughness effect using such relationships, including the popular Cooper [32,33] and Gorenflo [34] correlations.

Due to the importance of accurately accounting for the influence of surface roughness when correlating nucleate boiling data, and given the wide variety of conclusions that have been reached in previous investigations, further research is warranted. The goal of the present work is to provide additional insights into the role of surface roughness on nucleate pool boiling with an experimental exploration using two fluids with widely differing thermal properties and wetting characteristics: water and FC-77, a perfluorinated dielectric fluid. Widely used nucleate pool boiling correlations are evaluated against the experimental results. In particular, the capability of the correlations to account for the effect of surface roughness is of prime interest in this study.

\section{Experimental Setup}

2.1 Test Facility. The pool boiling test facility is shown in Fig. 1(a). The $25.4 \times 25.4 \mathrm{~mm}^{2}$ test surface is prepared on top of an aluminum test block. Heat is supplied through 12 cartridge heaters embedded in the test block. The arrangement of the cartridge heaters is shown in Fig. 1(b). Numerical simulations were performed to ensure that the cartridge heaters supplied heat uniformly to the test surface. Six thermocouple taps were drilled into the test block at two different vertical and three horizontal locations as shown in Fig. 1. Surface temperature measurements were determined by extrapolating the thermocouple readings. Type-T, $0.8 \mathrm{~mm}$ diameter sheathed thermocouples were used. All thermocouples were referenced to $0^{\circ} \mathrm{C}$ using a dry-block ice point reference chamber and the thermocouples were calibrated using a dry-block thermocouple calibration unit. The estimated uncertainty in the thermocouple measurements is $0.3^{\circ} \mathrm{C}$, while the estimated uncertainty in the extrapolated surface temperature ranges from $0.3^{\circ} \mathrm{C}$ at low heat fluxes to $0.6^{\circ} \mathrm{C}$ at higher heat fluxes.

A high temperature thermoplastic, PEEK, was chosen as an insulation material due to its combination of low thermal conductivity $(\sim 0.28 \mathrm{~W} / \mathrm{m} \mathrm{K})$, high temperature resistance (up to 
$250^{\circ} \mathrm{C}$ ), and good machinability. A ceramic (alumina silicate) sheath served as the insulation material around the hottest portion of the test block. The liquid pool was enclosed by clear polycarbonate walls to allow for direct observation of the boiling process. A thermocouple located in the pool (see Fig. 1 $(a)$ ) was used to measure the liquid pool temperature. Cartridge heaters installed inside the pool provided additional heat to maintain the liquid at the saturation temperature. Vapor generated from the boiling process flowed into a Graham-type condenser. The vapor inside the condenser was cooled and condensed using water from a chiller, with the condensate draining back into the pool, and the outlet open to the atmosphere in order to maintain atmospheric pressure inside the pool. Since, under high vapor loads, the condenser can become clogged with liquid, a pressure transducer monitors the pool pressure to ensure that it is indeed at atmospheric pressure throughout the experiments.

Establishing an effective seal between the test piece and the insulation proved to be difficult. Any gap or crack in this interface can result in unwanted nucleation sites. A solution to this problem was devised using an epoxy sealing technique. A very slight chamfer in the insulation block around the test surface formed a groove which provided space for a bead of sealant (as shown in the inset of Fig. 1(a)). A small bead of silicone RTV sealant was first applied to the bottom of the groove. A low-viscosity, slowcure epoxy filled the remaining portion of the groove. The RTV prevents the epoxy from wicking down the clearance gap between the test piece and insulation, thus allowing for easier removal of the test piece. Although undesirable nucleation sites were still occasionally detected with this technique, repeated testing indicated that these occasional unwanted nucleation sites have little effect on the results obtained.

The surface heat flux was determined by correcting the electrical power input by the amount of estimated heat loss. Although the axial pairs of thermocouples in the aluminum block could be used to measure the surface heat flux directly, this results in unacceptable errors in the measurement due to tolerances in the placement of the thermocouples and the thermocouple measurement uncertainties. Therefore, a 3D numerical simulation was performed to estimate the heat losses. The PEEK and ceramic insulation as well as the test block were included in the model and boundary conditions representative of the experimental test conditions were applied (uniform boiler surface temperature, uniform heat generation region for the cartridge heaters, and natural convection boundary conditions for the exterior surfaces). The numerically estimated heat losses were in reasonable agreement with the heat losses estimated based on thermocouple readings when considering the errors associated with this estimate. The heat losses were found to be less than $15 \%$ of the electrical power input for moderate to high heat fluxes $\left(q>120 \mathrm{~kW} / \mathrm{m}^{2}\right)$.

2.2 Test Surfaces. A total of six test pieces of varying surface roughness were fabricated. Separate test pieces were manufactured with a polished surface for use in the water and FC-77 experiments. In both cases, the polishing was achieved using successively finer grits of sandpaper. The other test pieces were manufactured with surfaces roughened to varying degrees. The surfaces were first fly-cut and then roughened using ram-type electrical discharge machining (EDM). In the EDM process, the machine parameters can be controlled to produce surfaces with different roughness. Enough surface material was removed with EDM so that the final roughness was solely due to the EDM process rather than the original machining operation.

The surface roughness of the test surfaces was measured with either a probe-type surface profilometer or an optical profilometer. Several scans were performed in different locations on each surface. The roughness average $\left(R_{a}\right)$, RMS roughness $\left(R_{q}\right)$, maximum profile peak height $\left(R_{p}\right)$, and five-point average maximum height $\left(R_{z}\right)$ were evaluated according to ASME B46.1-1995 standards and are reported in Table 1. No single roughness parameter
Table 1 Surface roughness measurements

\begin{tabular}{lcccc}
\hline \hline & \multicolumn{4}{c}{ Surface roughness parameters } \\
\cline { 2 - 5 } Surface preparation & $\begin{array}{c}R_{a} \\
(\mu \mathrm{m})\end{array}$ & $\begin{array}{c}R_{q} \\
(\mu \mathrm{m})\end{array}$ & $\begin{array}{c}R_{p} \\
(\mu \mathrm{m})\end{array}$ & $\begin{array}{c}R_{z} \\
(\mu \mathrm{m})\end{array}$ \\
\hline Polished (water) & 0.038 & 0.062 & 0.81 & 0.58 \\
Polished (FC-77) & 0.027 & 0.039 & 0.18 & 0.35 \\
EDM & 1.08 & 1.37 & 6.09 & 8.24 \\
& 2.22 & 2.81 & 12.0 & 16.7 \\
& 5.89 & 7.37 & 24.5 & 37.1 \\
& 10.0 & 12.5 & 32.4 & 56.5 \\
\hline \hline
\end{tabular}

has been shown to be superior for characterizing boiling surfaces and several surface parameters are being reported simply to allow an easier comparison to previous studies. However, it should be noted that the definition of some of these surface parameters has changed over time. For example, $R_{p}$ currently has congruent definitions in the ASME, ISO, and DIN standards, although the current definition differs from $R_{p \text {,old }}$ in DIN 4762/1:1960, which has been used by Stephan [28] among many other researchers. For the remainder of this paper, the roughness average $\left(R_{a}\right)$ will be used to identify the different surfaces under study.

The surface topography of four of the surfaces, as measured with the optical profilometer, is shown in Fig. 2. The polished surface (Fig. 2(a)) is seen to be quite smooth with a few small cavities distributed across the surface. EDM tends to form an irregular pattern of cavities on the surface (Figs. 2(b)-2(d)). The cavities are larger and more numerous on the EDM surfaces compared with the polished surface. The EDM surfaces with larger roughness form larger cavities than those with smaller RMS roughness.

2.3 Experimental Procedure. Deionized water and FC-77 were used as the test fluids; relevant thermophysical properties of the FC-77 are as follows: $T_{\text {sat }} \approx 100.3^{\circ} \mathrm{C}, \rho=1592 \mathrm{~kg} / \mathrm{m}^{3}, \mu$ $=4.42 \times 10^{4} \mathrm{~kg} / \mathrm{m} \mathrm{s}, \quad k_{l}=0.057 \mathrm{~W} / \mathrm{m} \mathrm{K}, \quad h_{f g}=89 \mathrm{~kJ} / \mathrm{kg}, \quad c_{p, l}$ $=1.170 \mathrm{~kJ} / \mathrm{kg} \mathrm{K}$, and $\sigma=0.0057 \mathrm{~N} / \mathrm{m}[35,36]$. The liquid was degassed by boiling for approximately $2 \mathrm{~h}$ prior to each experiment, either using the immersed cartridge heaters in the pool (for the FC-77 experiments) or in an external degassing reservoir (for the water experiments). During the experiments, heat losses from the pool required additional heat to be supplied through the immersed cartridge heaters to maintain the liquid at the saturation temperature. To mitigate undesirable convective currents induced by the immersed heaters, the power setting for the cartridge heaters was maintained as low as possible while maintaining the pool to within $0.5^{\circ} \mathrm{C}$ of the saturation temperature. At high heat fluxes, the pool cartridge heaters were turned off as the test piece provided enough heat by itself to maintain the desired pool temperature.

The thermocouple readings were recorded with a data acquisition system. All reported values of the surface temperature represent the average over an interval of at least $1 \mathrm{~min}$, after the surface temperature had reached equilibrium. Experiments were conducted both in order of increasing and decreasing heat flux to check for boiling hysteresis. The boiling process was observed through the front polycarbonate wall using a high-speed camera system with a macro lens. Illumination was provided by two fiberoptic illuminators and a halogen light source in the water experiments. A green laser light sheet served as the illumination source for the FC-77 experiments as this light source provided higher intensity and more uniform illumination that was necessary to resolve the smaller and more numerous vapor bubbles observed in the FC-77 experiments compared with the experiments in water. Images were recorded at frame rates between 8000 and 12,000 fps. 

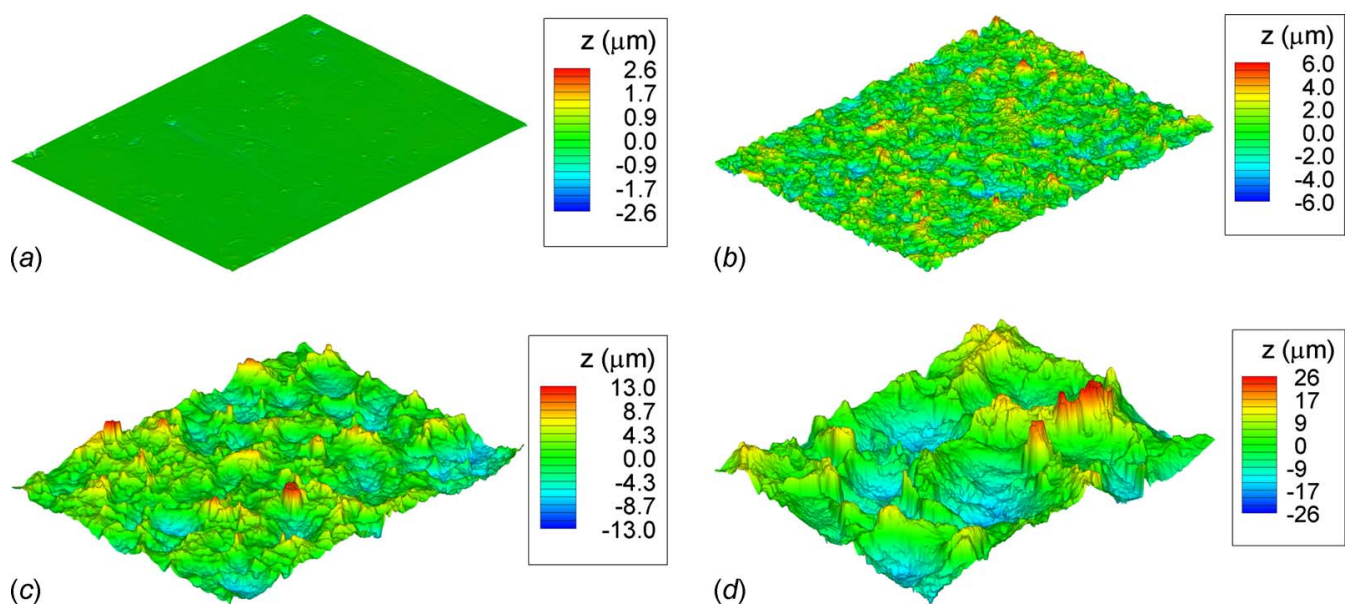

Fig. 2 Surface topography of test surfaces over an area of $400 \times 300 \mu \mathrm{m}^{2}$ as measured by an optical profilometer: (a) $0.038 \mu \mathrm{m}$ polished surface, (b) $1.08 \mu \mathrm{m}$ EDM surface, (c) $2.22 \mu \mathrm{m}$ EDM surface, and (d) $5.89 \mu \mathrm{m}$ EDM surface

\section{Experimental Results}

The boiling curves for water are shown in Fig. 3. The results are shown for data obtained in order of increasing heat flux (i.e., traversing "up" the boiling curve). As seen in Fig. 3(a), the roughest EDM surface $(10.0 \mu \mathrm{m})$ resulted in the lowest superheat at a given heat flux while the polished test piece $(0.038 \mu \mathrm{m})$ was associated with the highest superheat. The other EDM test surfaces of intermediate roughness $(1.08 \mu \mathrm{m}, 2.22 \mu \mathrm{m}$, and $5.89 \mu \mathrm{m})$ performed similarly, resulting in lower superheats than the polished test piece but higher superheats than the roughest EDM surface. The $5.89 \mu \mathrm{m}$ surface had slightly higher superheats than the $1.08 \mu \mathrm{m}$ and $2.22 \mu \mathrm{m}$ surfaces at lower heat fluxes but the results show negligible difference in superheat at higher heat fluxes. Boiling incipience occurred at a superheat of approximately $5^{\circ} \mathrm{C}$ for the roughest EDM surface $(10.0 \mu \mathrm{m})$, $7^{\circ} \mathrm{C}$ for the other EDM surfaces $(1.08 \mu \mathrm{m}, 2.22 \mu \mathrm{m}$, and $5.89 \mu \mathrm{m})$, and $11^{\circ} \mathrm{C}$ for the polished surface. This may be attributed to the rougher surfaces having larger active cavity sizes, which result in lower wall superheats at incipience. The heat transfer coefficients show a similar trend (Fig. 3(b)). The roughest
EDM surface achieved the highest heat transfer coefficient for a given heat flux while the polished test piece resulted in the lowest. The $1.08 \mu \mathrm{m}, 2.22 \mu \mathrm{m}$, and $5.89 \mu \mathrm{m}$ surfaces showed approximately a $60 \%$ improvement in the heat transfer coefficient over the polished surface at a given heat flux, while the 10.0 $\mu \mathrm{m}$ EDM surface provided approximately a $100 \%$ improvement.

As discussed earlier, several researchers have concluded that once a surface is sufficiently rough, there is no benefit to additional roughening [17-19]. If the $10.0 \mu \mathrm{m}$ surface is excluded, the current study would support this conclusion as there is no additional enhancement beyond $R_{a}=1.08 \mu \mathrm{m}$. It is possible that if the roughness were increased significantly in the past studies, a trend similar to the findings in the current study may have held true. However, it is currently unclear why the $10.0 \mu \mathrm{m}$ surface performs markedly better than the other EDM surfaces (in repeated tests), and it is difficult to conclusively address this issue. The roughest EDM surface had a lower incipience superheat and higher heat transfer coefficients than the other EDM surfaces. The surface area in contact with the fluid for the $10.0 \mu \mathrm{m}$ EDM surface, estimated from the optical profilometer data, was only ap-
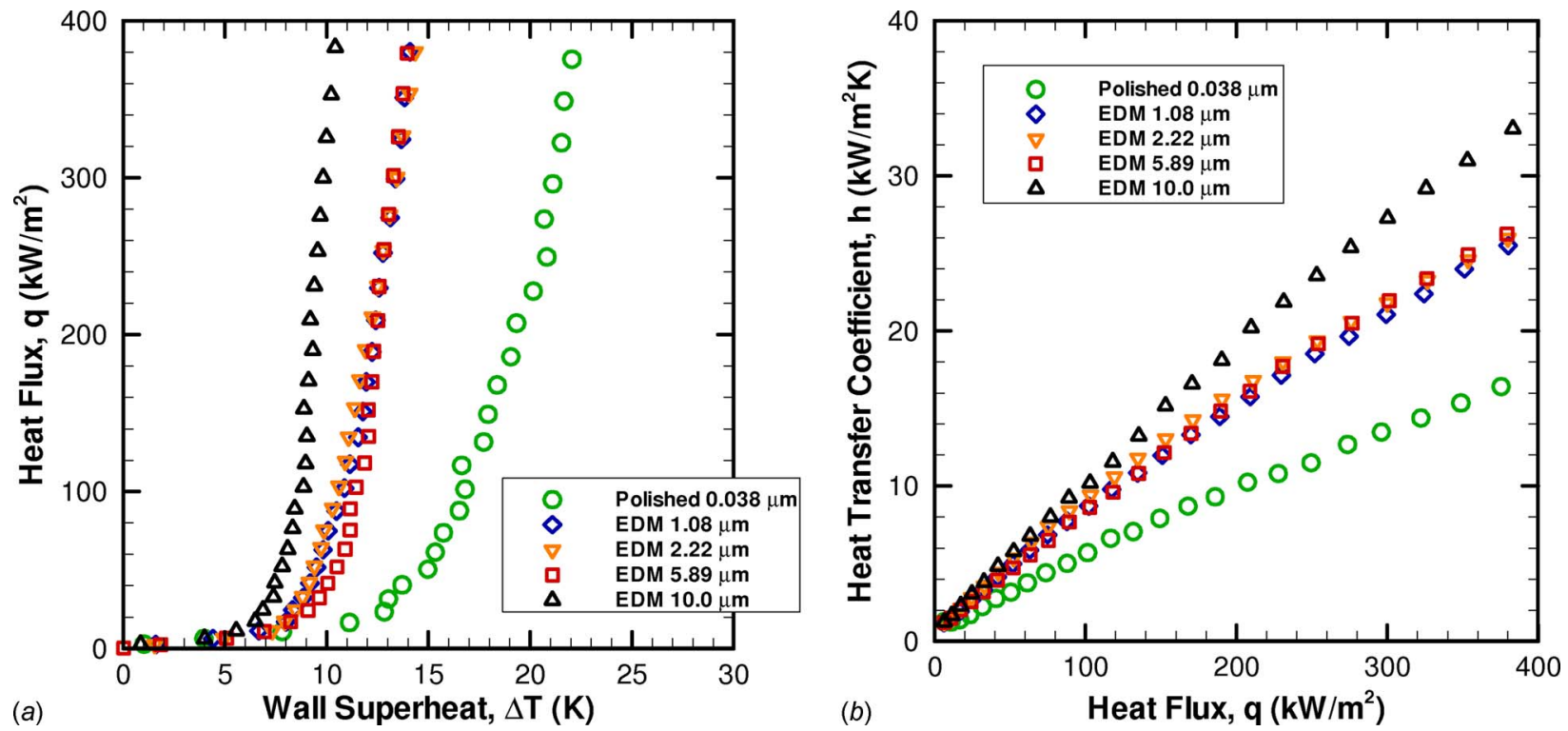

Fig. 3 Boiling curves for water: (a) heat flux versus wall superheat and (b) heat transfer coefficient versus heat flux 

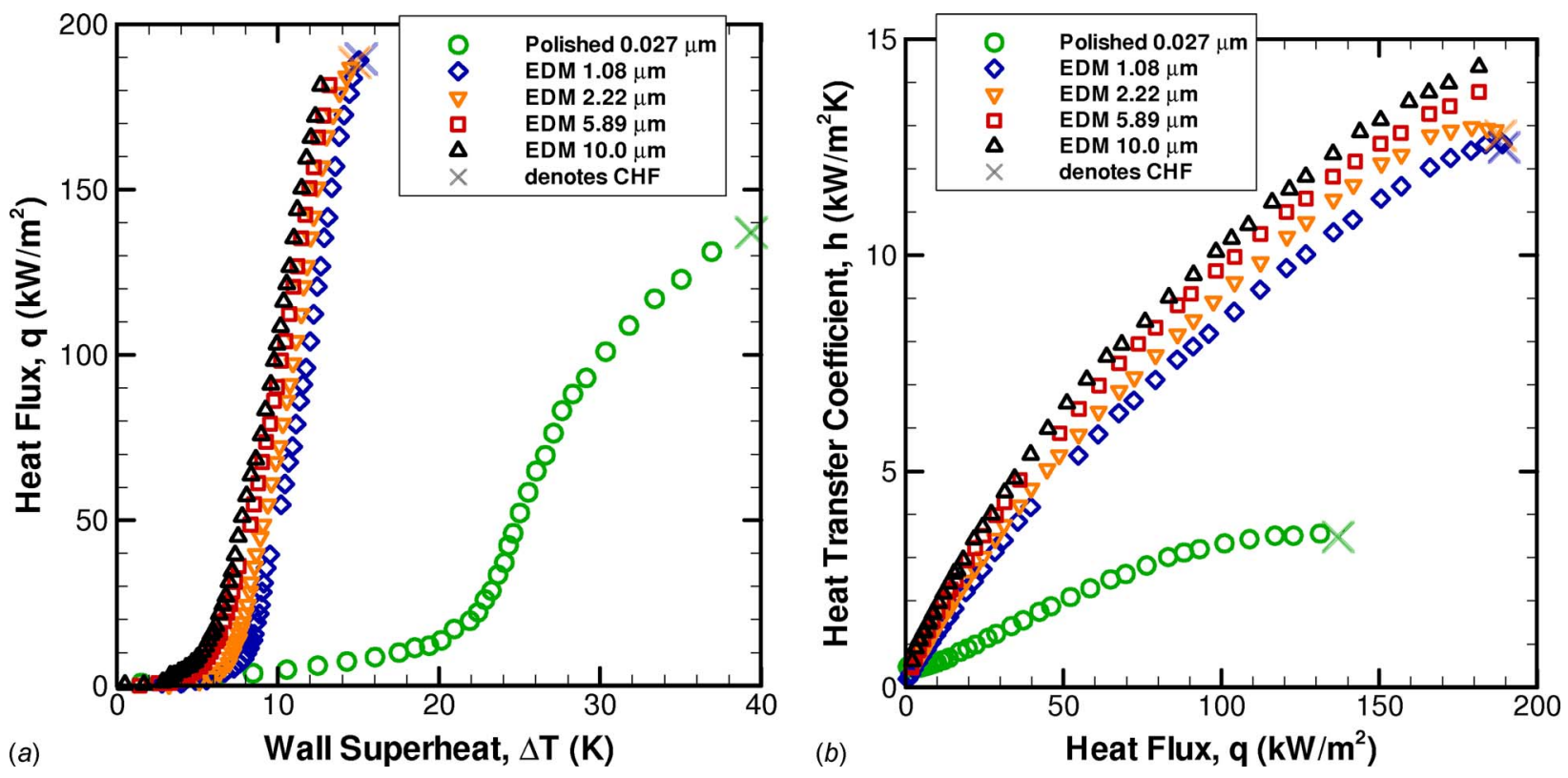

Fig. 4 Boiling curves for FC-77: (a) heat flux versus wall superheat and (b) heat transfer coefficient versus heat flux

proximately $1 \%$ greater than for the $5.89 \mu \mathrm{m}$ surface. Therefore, a surface area enhancement does not explain the higher heat transfer coefficients observed. It appears that the $10.0 \mu \mathrm{m}$ EDM surface has larger active cavities and a higher active cavity density than the other EDM surfaces. These results, as other researchers have concluded, highlight the inadequacy in using standard surface roughness parameters to characterize boiling surfaces.

The boiling curves for FC-77 are shown in Fig. 4. The results are shown for data obtained in order of decreasing heat flux (i.e., traversing "down" the boiling curve). Hysteresis effects (i.e., comparison of data obtained while traversing "up" the boiling curve versus "down" the curve) are discussed later in this section. Unlike the results in water, a trend of continuously increasing heat transfer coefficients with respect to surface roughness, for a given heat flux, is observed in the FC-77 experiments. There also appears to be a larger dependence of heat transfer coefficient on surface roughness for FC-77 than for water. The improvements in heat transfer coefficient range from $150 \%$ for the $1.08 \mu \mathrm{m}$ surface to $210 \%$ for the $10.0 \mu \mathrm{m}$ surface above the values obtained for the polished surface, at a fixed heat flux. The differences in the observed trends in the heat transfer coefficient between water and FC-77 may be attributed to the differences in wetting behavior of the two fluids as well as the cavity size distribution presented by the surfaces. Since FC-77 is more highly wetting than water, smaller cavities are preferred for nucleation. For instance, it is possible that the $1.08 \mu \mathrm{m}$ and $5.89 \mu \mathrm{m}$ surfaces have a similar number of the larger cavities that cause nucleation in water, yet the $5.89 \mu \mathrm{m}$ surface may have a greater number of the smaller cavities that cause nucleation in FC-77. However, evaluation of the surfaces for cavity size distribution is not straightforward even when detailed 3D surface profiles are available, and the reasons for the observed differences between water and FC-77 need further study.

The value of critical heat flux, depicted with an $\times$ in Fig. 4, was experimentally determined for the polished, $1.08 \mu \mathrm{m}$, and $2.22 \mu \mathrm{m}$ surfaces in FC-77. It can be seen in Fig. 4(b) that the boiling curves tend to flatten out as critical heat flux is approached, as is most apparent with the polished surface. The polished surface exhibited a critical heat flux of $137 \mathrm{~kW} / \mathrm{m}^{2}$, while higher and nearly identical values of critical heat flux of 189 and $188 \mathrm{~kW} / \mathrm{m}^{2}$ were observed for the $1.08 \mu \mathrm{m}$ and $2.22 \mu \mathrm{m}$ EDM surfaces, respectively, showing an almost $40 \%$ improvement. Due to the limit on the condenser capability with respect to maximum vapor generation rates, the experiments were not run to critical heat flux values with the two roughest surfaces for FC-77 and for any of the surfaces in water.

Additional experiments were conducted to check for boiling hysteresis (see Fig. 5). For water (Fig. 5(a)), the roughest EDM test piece showed no discernible hysteresis, with the results obtained during increasing $(q \uparrow)$ and decreasing $(q \downarrow)$ heat flux being nearly identical. However, some extent of hysteresis was observed for the polished test piece in water. At the incipience heat flux $\left(\sim 15 \mathrm{~kW} / \mathrm{m}^{2}\right)$, the wall superheat is approximately $10.8^{\circ} \mathrm{C}$ in the direction of increasing heat flux $(q \uparrow)$, while it was only $9.5^{\circ} \mathrm{C}$ for decreasing heat flux $(q \downarrow)$. The maximum disparity in the superheat between the increasing and decreasing curves occurs at a heat flux of $2.0 \mathrm{~W} / \mathrm{cm}^{2}$, corresponding to a temperature overshoot of $2.3^{\circ} \mathrm{C}$. Hysteresis has generally not been reported in the literature for water at atmospheric pressure, although such effects have been observed for water at subatmospheric pressures [37]

Large hysteresis effects on smooth surfaces have been widely reported for FC fluids [38-40] and highly wetting fluids in general $[8,41]$. Accordingly, a large temperature overshoot of $16 \cdot 8^{\circ} \mathrm{C}$ was observed for the polished surface (see Fig. 5(b)). The EDM surfaces also exhibit noticeable hysteresis effects with FC-77. A maximum temperature overshoot of $16.2^{\circ} \mathrm{C}$ was measured for the $1.08 \mu \mathrm{m}$ EDM surface, which is comparable to the measured overshoot for the polished surface, although much lower surface temperatures are obtained with the EDM surface. The $10.0 \mu \mathrm{m}$ EDM surface had a much reduced, although still significant, temperature overshoot of $5.6^{\circ} \mathrm{C}$. It should also be noted that past boiling history has been shown to have a strong influence on the observed hysteresis $[8,38,42]$, although this has not been studied in detail in the present work.

Photographs of the boiling process taken with the high-speed camera system are shown in Fig. 6 for water and in Fig. 7 for FC-77. At low heat fluxes close to the incipience heat flux $\left(50 \mathrm{~kW} / \mathrm{m}^{2}\right.$ for water and $20 \mathrm{~kW} / \mathrm{m}^{2}$ for FC-77 as seen in Figs. 6 and 7, respectively), significantly more active nucleation sites can be observed in the roughened EDM surface relative to the polished surface. Furthermore, the $5.89 \mu \mathrm{m}$ EDM surface has a smaller bubble departure diameter and a higher bubble emission frequency than the polished surface. The reasons for the differ- 

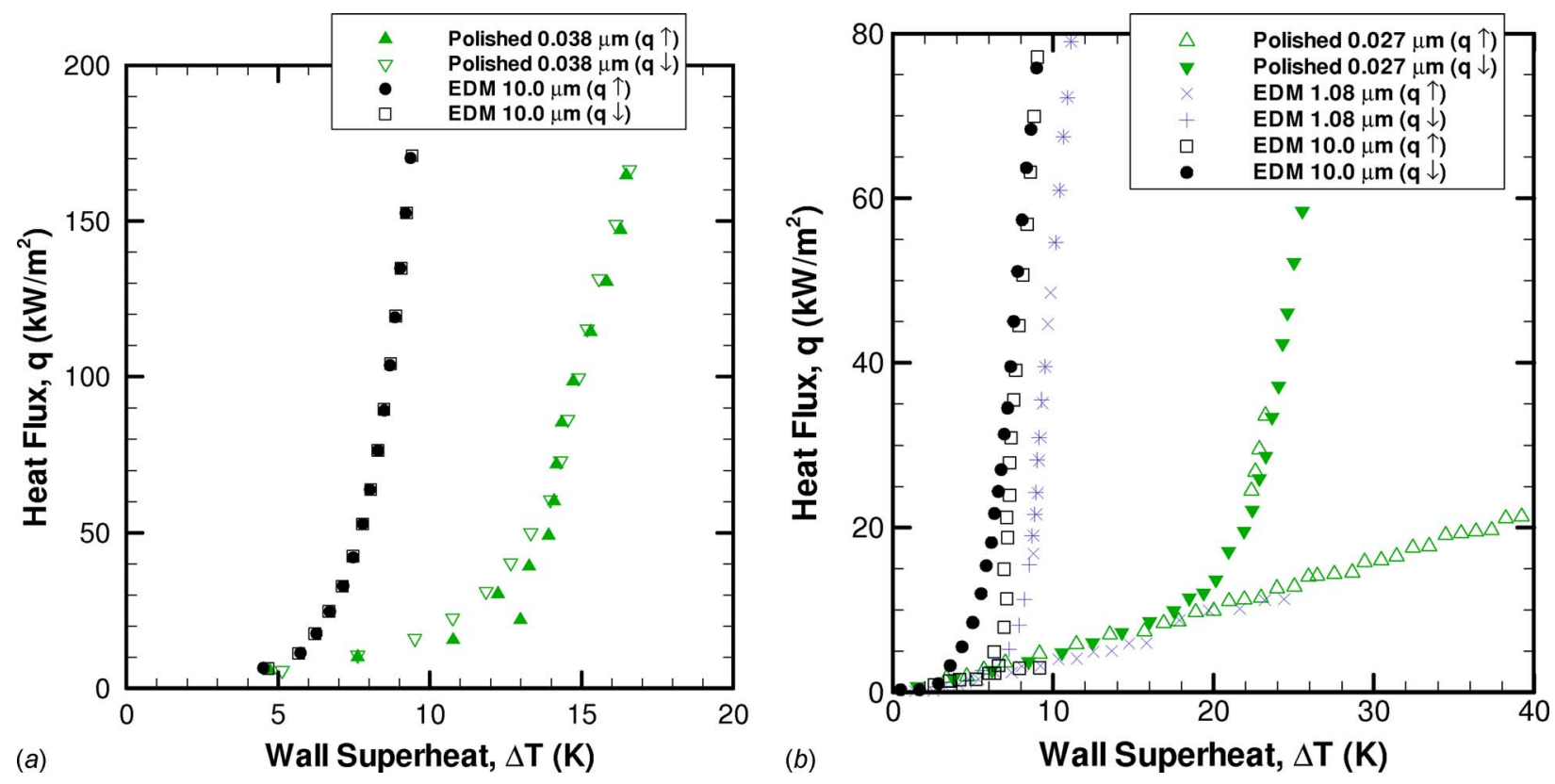

Fig. 5 Boiling curves showing the hysteresis effect for (a) water and (b) FC-77, where $q \uparrow$ indicates data obtained in order of increasing heat flux and $q \downarrow$ indicates those in order of decreasing heat flux. It is noted that a smaller heat flux increment was used experimentally than is indicated in $(b)$; only a fraction of the data are included to improve readability of the figure.

ences in bubble departure size for the different surfaces were explained by Hatton and Hall [43]. Hatton and Hall considered all of the forces acting on a bubble during the growth process. For small cavity sizes, the bubble departure size is mainly determined by a balance between the buoyancy and the dynamic inertial forces. As the cavity size increases, the inertial forces decrease and the bubble departure diameter decreases, which explains the decreased bubble diameters from the EDM surfaces. For large cavities, a balance between buoyancy and surface tension forces determines the departure size.
At higher heat fluxes, the sizes of bubbles issuing from the smooth surface are similar to those issuing from the roughened surface due to a merging of bubbles from adjacent nucleation sites. This is most clearly seen in Fig. 6 at a heat flux of $100 \mathrm{~kW} / \mathrm{m}^{2}$ for water and in Fig. 7 at a heat flux of $80 \mathrm{~kW} / \mathrm{m}^{2}$ for FC-77. As the heat flux is further increased, vapor slugs and columns are formed, as can be observed in the last row of photographs in Fig. 6. For water at $210 \mathrm{~kW} / \mathrm{m}^{2}$, it is still apparent that the roughened surface has a greater number of active nucleation
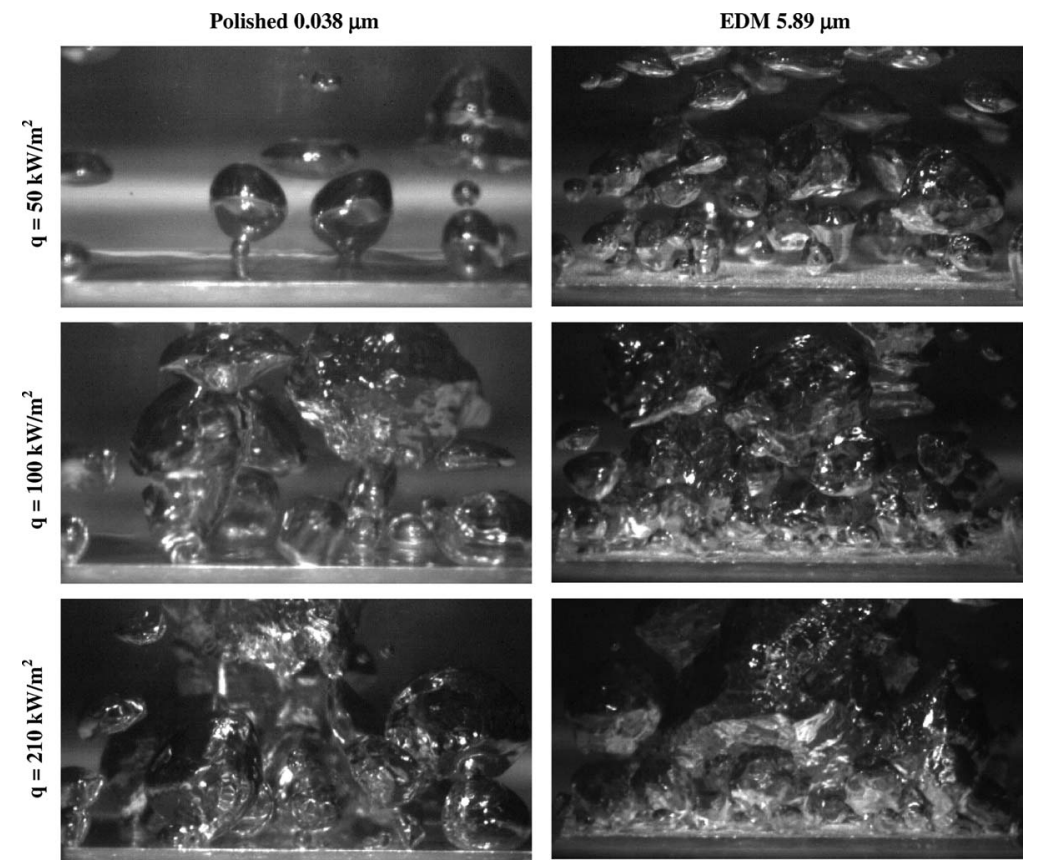

Fig. 6 Photographs of the boiling process in water for varying heat flux and surface roughness. The physical width of each image is approximately $25 \mathrm{~mm}$. 

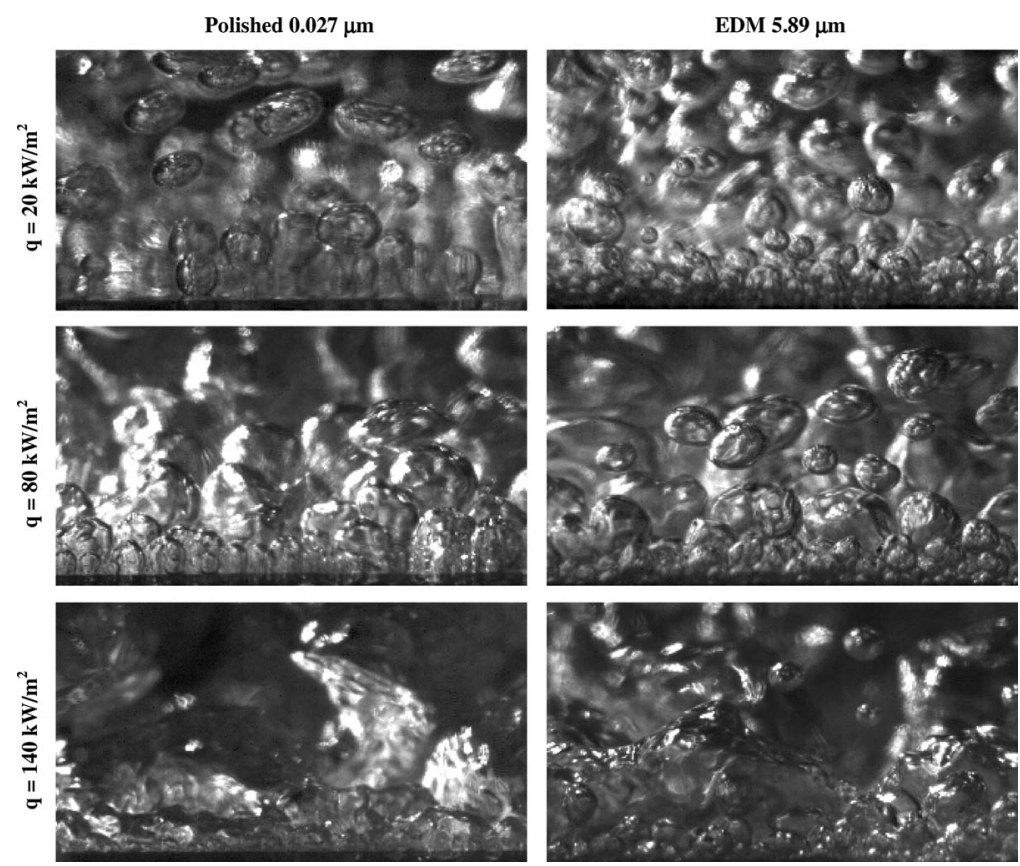

Fig. 7 Photographs of the boiling process in FC-77 for varying heat flux and surface roughness. The physical width of each image is approximately $7.3 \mathrm{~mm}$.

sites than the polished surface. For FC-77 at $140 \mathrm{~kW} / \mathrm{m}^{2}$, both the polished and rough surfaces are close to being blanketed by the vapor as the heat flux is approaching the critical value.

Some other interesting visual differences in the boiling behavior between water and FC-77 were also observed. For water, bubbles first nucleated from a single site and as the heat flux was incrementally increased, additional nucleate sites became active, more or less randomly distributed across the test surface. For FC77, however, nucleation sites tended to spread from the initial bubble-generating site as the heat flux was increased while the rest of the surface remained free of active centers (although this is not evident in Fig. 7 since only a small portion of the surface is shown). The boiling patch would continue to grow until the heat flux was sufficient to activate sites across the entire surface. This patchwise boiling phenomenon has been previously reported by other investigators such as Corty and Foust [8] and Bergles and Chyu [42].

\section{Discussion}

4.1 Influence of Surface Roughness on the Boiling Curve. It is well known that nucleate boiling heat transfer can be well represented by an exponential relationship given by $h \propto q^{n}$, where $n$ is a function of pressure and surface characteristics. As was mentioned earlier, several researchers have also noted that the dependence of heat transfer coefficient on surface roughness (at a fixed heat flux) can be modeled by an exponential relation, $h$ $\propto R^{m}$, where $R$ is some measure of the surface roughness. Putting these two relationships together yields

$$
h=C R^{m} q^{n}
$$

where $C$ is a constant. As Eq. (1) indicates, surface roughness can both change the magnitude of the heat transfer coefficient and change the slope of its variation with heat flux since the exponent $n$ is also dependent on roughness. In this section, the $h \propto R^{m}$ relationship is first examined, followed by the influence of surface roughness on the slope of the $h$ versus $q$ variation.

The effect on heat transfer coefficient of the surface roughness at different heat fluxes is illustrated in Fig. 8. An exponential curve represents the experimental results reasonably well, with some deviation from the trend exhibited in Fig. 8(a) by the $5.89 \mu \mathrm{m}$ surface in water. The roughness exponent $m$ changes only mildly with heat flux. For water, the roughness exponent is 0.09 at $50 \mathrm{~kW} / \mathrm{m}^{2}$ and $100 \mathrm{~kW} / \mathrm{m}^{2}$ and increases slightly to $m$ $=0.11$ at a heat flux of $300 \mathrm{~kW} / \mathrm{m}^{2}$. With FC-77 (see Fig. 8(b)), a greater dependence of surface roughness on the heat transfer coefficient is seen than with water, resulting in higher roughness exponents ranging from $m=0.21$ at $20 \mathrm{~kW} / \mathrm{m}^{2}$ to $m=0.19$ at $80 \mathrm{~kW} / \mathrm{m}^{2}$. The EDM surfaces for FC-77 seem to be better represented by a different slope than the overall curve (the latter includes the polished surface). The roughness exponents for the EDM surfaces alone range from $m=0.15$ at $20 \mathrm{~kW} / \mathrm{m}^{2}$ to $m$ $=0.09$ at $80 \mathrm{~kW} / \mathrm{m}^{2}$.

The results indicate that the surface roughness exponent is not a constant across different fluid-surface combinations. Since it is well known that the wettablity of the fluid has important consequences on the nucleation behavior [23], it is reasonable to hypothesize that $m$ is also a function of the contact angle. Although contact angles were not measured in the current study, FC-77 is highly wetting on most metal surfaces while water is moderately wetting. Therefore, it may be proposed that highly wetting fluids are well represented by a roughness exponent $m=0.2$ while for moderately wetting fluids, $m=0.1$ is more appropriate. However, it is noted that the difference in slopes between the overall curves and the EDM-only curves for FC-77 and the anomalously low value of the heat transfer coefficient for the $5.89 \mu \mathrm{m}$ surface in water cannot be reconciled if $m$ is simply a function of contact angle $(\theta)$. This further illustrates the weakness in using $R_{a}$ to correlate the nucleate boiling data and highlights the deficiencies in models of the form $h \propto R^{m}$. That said, although the model does not account for all of the inconsistencies that numerous other authors have observed when trying to correlate the effects of roughness, it does serve as a useful basis for developing nucleate boiling correlations, as will be further discussed later.

Table 2 provides a summary of findings in the literature regarding the dependence of heat transfer coefficient on surface roughness. Most of the studies were conducted using refrigerants with 

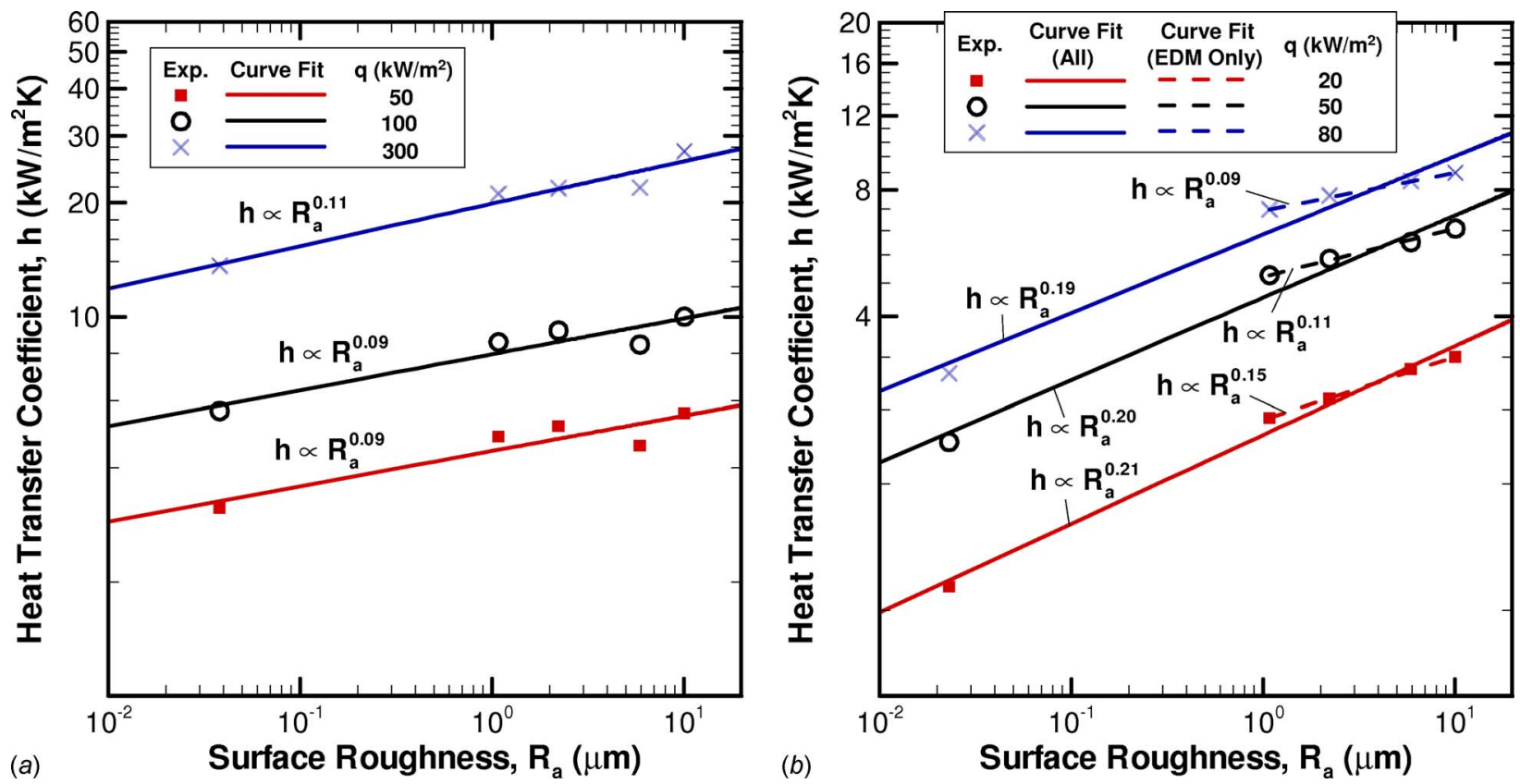

Fig. 8 Dependence of heat transfer coefficient on surface roughness for (a) water and (b) FC-77. The solid lines represent a curve fit through all five experimental data points (one polished surface and four EDM surfaces). The dashed lines in (b) represent a curve fit to only the four EDM surfaces (excluding the $0.027 \mu \mathrm{m}$ polished surface).

the exception of Fedders [44] and the current study, where water is considered. Moreover, most past studies were conducted at low reduced pressure and only in the study by Nishikawa et al. [30,31] was a wide range of reduced pressures investigated. As stated earlier, Nishikawa et al. found that $m=0.2\left(1-P_{r}\right)$, which reduces to $m \approx 0.2$ at low reduced pressures. This seems to agree well with the findings of Danilova and Bel'skii [29] and Ribatski and Jabardo [45], but conflicts with the value proposed by Stephan [28]. A surface roughness exponent of $m=0.2$ also agrees with the current results in FC-77. If the hypothesis that $m=f(\theta)$ holds, this is not entirely surprising since most refrigerants are highly wetting on metal surface. Of the results in water, Fedders [45] found $m$ to range from 0.10 to 0.133 , which agrees reasonably well with the present $m$ values $(0.09$ to 0.11$)$ for water. However, these $m$ values in water also agree with Stephan's [28] $m=0.133$ in R11, which does not support the claim that $m$ is a function of $\theta$. Thus, more experimental investigations are needed to clarify whether $m$ $=f(\theta)$ is an adequate generalization of the influence of surface roughness.

Table 2 Dependence of heat transfer coefficient on surface roughness

\begin{tabular}{|c|c|c|c|c|c|c|c|c|}
\hline Author(s) & Dependence & Pressure & $\begin{array}{l}\text { Heat flux } \\
\left(\mathrm{W} / \mathrm{m}^{2}\right)\end{array}$ & Fluid(s) & $\begin{array}{c}\text { Heater } \\
\text { type }\end{array}$ & $\begin{array}{l}\text { Surface } \\
\text { material }\end{array}$ & $\begin{array}{c}\text { Surface } \\
\text { preparation }\end{array}$ & $\begin{array}{l}\text { Roughness } \\
(\mu \mathrm{m})\end{array}$ \\
\hline Stephan $[28]$ & $h \propto R_{p, \text { old }}^{0.133}$ & $P_{r}=0.023$ & $5 \times 10^{4}$ & $\mathrm{R}-11$ & $\begin{array}{l}\text { horizontal } \\
\text { cylinder, } \\
\text { horizontal } \\
\text { plate }\end{array}$ & copper & not specified & $0.15<R_{p, \text { old }}<7.9$ \\
\hline $\begin{array}{l}\text { Danilova and } \\
\text { Bel'skii [29] }\end{array}$ & $h \propto R_{z}^{0.2}$ & $0.118<P_{r}<0.155$ & $10^{4}$ & R-12, R-114 & $\begin{array}{l}\text { horizontal } \\
\text { cylinder }\end{array}$ & $\begin{array}{l}\text { cooper, } \\
\text { steel }\end{array}$ & $\begin{array}{l}\text { sandpaper, } \\
\text { sandblasted, } \\
\text { turning, etc. }\end{array}$ & $0.3<R_{z}<58$ \\
\hline $\begin{array}{l}\text { Nishikawa } \\
\text { et al. }[30,31]\end{array}$ & $h \propto R_{p, \text { old }}^{0.2\left(1-P_{r}\right)}$ & $0.08<P_{r}<0.9$ & $10^{5}$ & $\begin{array}{c}\mathrm{R}-12, \mathrm{R}-113 \\
\mathrm{R}-114\end{array}$ & $\begin{array}{l}\text { horizontal } \\
\text { plate }\end{array}$ & copper & emery cloth & $0.022<R_{p, \text { old }}<4.31$ \\
\hline \multirow{3}{*}{ Fedders [44] } & $h \propto R_{p, \text { old }}^{0.133}$ & $0.012<P_{r}<0.089$ & $5 \times 10^{4}$ & \multirow{3}{*}{ water } & \multirow{3}{*}{$\begin{array}{l}\text { horizontal } \\
\text { cylinder }\end{array}$} & \multirow{3}{*}{ stainless steel } & \multirow{3}{*}{$\begin{array}{l}\text { sandpaper, } \\
\text { sandblasted }\end{array}$} & \multirow{3}{*}{$0.18<R_{p, \text { old }}<3.6$} \\
\hline & $h \propto R_{p, \text { old }}^{0.12}$ & $P_{r}=0.012$ & \multirow{2}{*}{$10^{6}$} & & & & & \\
\hline & $h \propto R_{p, \text { old }}^{0.10}$ & $P_{r}=0.089$ & & & & & & \\
\hline $\begin{array}{l}\text { Ribatski and } \\
\text { Jabardo [45] }\end{array}$ & $h \propto R_{a}^{0.2}$ & $0.008<P_{r}<0.260$ & not specified & $\begin{array}{c}\text { R-11, R-123, } \\
\text { R-12, R-134a, } \\
\text { R-22 }\end{array}$ & $\begin{array}{l}\text { horizontal } \\
\text { cylinder }\end{array}$ & $\begin{array}{l}\text { copper, brass, } \\
\text { stainless steel }\end{array}$ & $\begin{array}{l}\text { sandpaper, } \\
\text { sandblasted }\end{array}$ & $0.02<R_{a}<3.3$ \\
\hline \multirow{2}{*}{ Current work } & $h \propto R_{a}^{0.1}$ & $P_{r}=0.0046$ & $5 \times 10^{4}$ to $3 \times 10^{5}$ & water & \multirow{2}{*}{$\begin{array}{l}\text { horizontal } \\
\text { plate }\end{array}$} & \multirow{2}{*}{ aluminum } & \multirow{2}{*}{$\begin{array}{l}\text { sandpaper, } \\
\text { EDM }\end{array}$} & $0.038<R_{a}<10.0$ \\
\hline & $h \propto R_{a}^{0.2}$ & $P_{r}=0.064$ & $2 \times 10^{4}$ to $8 \times 10^{4}$ & FC-77 & & & & $0.027<R_{a}<10.0$ \\
\hline
\end{tabular}




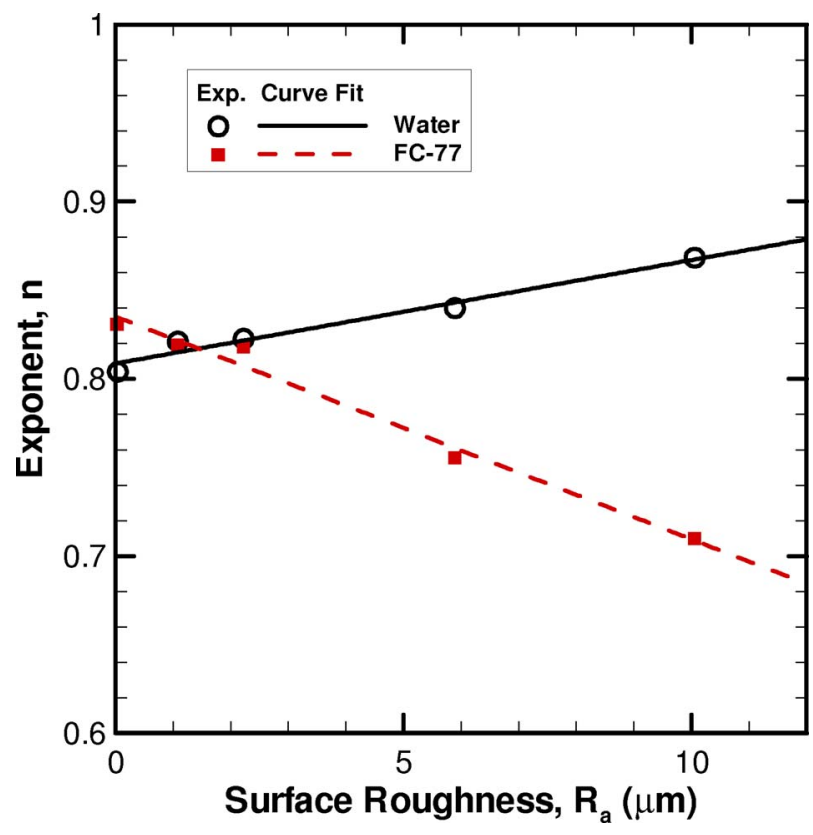

Fig. 9 Dependence of heat flux exponent $\boldsymbol{n}$ in the relationship $h \propto q^{n}$ on surface roughness

From Table 2 it does not appear that heater type (horizontal cylinder versus horizontal flat plate) has a discernible effect on the surface roughness exponent. Stephan [28] studied both horizontal cylinders and flat surfaces and found that a roughness exponent of $m=0.133$ was representative of both heater types. Few studies have investigated the effects of surface roughness on vertical cylinders and flat plates. Although Chun and Kang's [46] study of surfaces over a small range of surface roughness $\left(R_{q}\right.$ between $0.0151 \mu \mathrm{m}$ and $0.0609 \mu \mathrm{m})$ found that vertical tubes are affected by surface roughness to a greater extent than horizontal tubes, there is no further confirmation in the literature of this trend, and it is currently unclear that a modification in surface roughness exponent $m$ is needed to account for tube orientation.

The role of the surface material on the surface roughness exponent is not conclusive. In Danilova and Bel'skii's [29] study, both copper and steel surfaces were used and no noticeable difference in the trend of heat transfer coefficient with surface roughness was noted for the two surface materials. While Ribatski and Jabardo [45] also studied a variety of surface materials, most of their work on the effects of surface roughness dealt with copper surfaces. Since the surface material and other surface characteristics (degree of oxidation, coatings, etc.) influence the contact angle $\theta$, the choice of material may influence $m$ if it is indeed a function of $\theta$. However, to the authors' knowledge, this has not been experimentally explored in detail.

The present results show that the heat flux exponent $n$ changes with roughness since the exponent $m$ in the relationship $h \propto R^{m}$ was found to change with heat flux. The relationship between $n$ and $R_{a}$ thus warrants a closer investigation. As shown in Fig. 9, the exponent $n$ is found to vary linearly with surface roughness from 0.80 for the polished to 0.87 for the roughest EDM surfaces in water; the corresponding variation in $n$ for $\mathrm{FC}-77$ is from 0.83 to 0.71 .

The findings from the present work may be compared with a number of studies in the literature. The data provided by Vachon et al. $[17,47,48]$ for water at atmospheric pressure suggest exponents $n$ in the relationship $h \propto q^{n}$ in the same range as the present study. However, data by Vachon et al. for chemically etched surfaces exhibit higher exponents $n$ than their data for the unidirectional polished surfaces despite having similar surface roughness. The experimental data for water by Kurihara and Myers $[9,49]$ show a much stronger dependence on surface roughness on the slope of the boiling curve than observed in the current study. As determined from the data provided in Ref. [49], the exponent $n$ varies from 0.76 to 0.95 from the smoothest to the roughest surface. Although Kurihara and Myers [9] did not state the surface roughness, it was implied that the rms roughness was less than $1.2 \mu \mathrm{m}$. Based on these comparisons, it does not appear that $n$ can be adequately correlated with surface roughness. However for the current results, the ability to predict the change in the exponent $n$ with roughness is of secondary importance since only small changes in the slope were noted ( $n$ ranging from 0.80 to 0.87 for $R_{a}$ ranging from $0.038 \mu \mathrm{m}$ to $10.0 \mu \mathrm{m}$, respectively, in water).

4.2 Nucleate Boiling Correlations. The complex liquidvapor-surface phenomena involved in nucleate pool boiling heat transfer has rendered the development of a predictive model difficult, as is evident from the large number of nucleate boiling correlations that have been proposed over the past several decades (see Table 3). Many of these correlations have theoretical underpinnings, such as the correlation by Forster and Zuber [50]; however, their utility is limited by the failure to adequately account for surface effects. One of the earliest correlations developed specifically to handle a wide variety of fluids and surfaces is the Rohsenow [51] correlation, which uses empirical factors to account for the surface-fluid combination. Constants for several surface-fluid combinations have been provided by various authors [52,53] However, the usefulness of the Rohsenow correlation is also limited as it requires experimental data on the fluid-surface combination of interest as inputs.

Several correlations have been formulated in terms of nucleation site densities to represent the influence of different surface characteristics on heat transfer. These include the correlations by Tien [54], Leinhard [55], and Mikic and Rohsenow [56]. However, since the nucleation site densities are generally not known a priori, most of these correlations require empirical fits to determine these parameters and other associated constants. Although these correlations are still of some theoretical significance, their utility in many engineering environments is limited.

As noted earlier, several investigators have observed a $h \propto R^{m}$ dependence and correlations adopting a form similar to Eq. (1) have been proposed. These include the correlations by Danilova [57], Nishikawa et al. [31], Cooper [32,33], Gorenflo [34], Leiner [58], and Ribatski and Jabardo [45]. Most of these correlations provide predictions of nucleate pool boiling heat transfer coefficients without the need for experimental data as inputs; thus, these correlations have proven quite useful in many engineering applications. The Danilova, Nishikawa, and Ribatski and Jabardo correlations were developed specifically for refrigerants; while the Cooper, Gorenflo, and Leiner correlations were designed for a broader range of fluids. Since it is highly desirable to have a single correlation that provides accurate predictions for a wide variety of fluid-surface combinations, further discussion in this work is limited to the Cooper, Gorenflo, and Leiner correlations. The suitability of each of these correlations for predicting the nucleate pool boiling heat transfer coefficients from the present work for two fluids (water and FC-77) with significantly different wetting characteristics and thermal properties over a wide range of surface roughness is assessed.

4.3 Cooper Correlation. Cooper [59] noticed that although many correlations had different algebraic forms, they produced similar numerical predictions and similar trends. He showed that many of these correlations could be reformulated using reduced properties, resulting in a simpler formulation without much loss in accuracy $[32,33]$. The Cooper correlation (see Table 3) accounts for the surface roughness effect using the relation developed by Nishikawa et al. [30,31]. However, Cooper reformulated the $\left(8 R_{p, \text { old }}\right)^{0.2\left(1-P_{r}\right)}$ relationship suggested by Nishikawa et al. into $P_{r}^{0.12-0.2 \log _{10} R_{p}}$. Cooper [33] found that the reformulated expression matched the original expression by Nishikawa et al. within 
Table 3 Nucleate boiling correlations

\begin{tabular}{|c|c|}
\hline Author(s) & Correlation \\
\hline Forster and Zuber [50] & $q=C k_{l} \operatorname{Pr}_{l}^{b}\left[\frac{h_{f g} \rho_{v}}{c_{p, l} \rho_{l} \sqrt{\pi \alpha_{l}}}\left(\frac{\Delta P}{2 \sigma}\right)^{0.5}\left(\frac{\Delta P}{\rho_{l}}\right)^{0.25}\right]\left[\frac{\rho_{l}}{\mu_{l}}\left(\frac{\Delta T c_{p, l} \rho_{l} \sqrt{\pi \alpha_{l}}}{h_{f g} \rho_{v}}\right)^{2}\right]^{a}$ \\
\hline Rohsenow [51] & $q=\mu_{l} h_{f g} \sqrt{\frac{g\left(\rho_{l}-\rho_{v}\right)}{\sigma}}\left[\frac{c_{p, l} \Delta T}{C h_{f g} \operatorname{Pr}_{l}^{b}}\right]^{a}$ \\
\hline Tien $[54]$ & $q=C k_{l} \operatorname{Pr}_{l}^{0.33} N^{0.5} \Delta T$ \\
\hline Lienhard [55] & $q=C k_{l} \operatorname{Pr}^{1 / 3} \frac{\sqrt{\sigma g\left(\rho_{l}-\rho_{v}\right) / \rho_{l}^{2}}}{\sqrt{\sigma g\left(\rho_{l}-\rho_{v}\right) /\left.\rho_{l}^{2}\right|_{\mathrm{H}_{2} \mathrm{O}}}} N^{1 / 3}(\Delta T)^{5 / 4}$ \\
\hline Mikic and Rohsenow [56] & $q=C\left(k_{l} \rho_{l} c_{p, l} f\right)^{1 / 2} d_{0}^{2} N \Delta T$ \\
\hline Danilova [57] & $h=C\left(\frac{R_{z}}{R_{z 0}}\right)^{0.2}\left(0.14+2.2 P_{r}\right) q^{0.75}$ \\
\hline Nishikawa et al. [31] & $h=\left(31.4 \frac{P_{c}^{0.2}}{M^{0.1} T_{c}^{0.9}}\right)\left(8 R_{p, \text { old }}\right)^{\left(1-P_{r}\right) / 5}\left[\frac{P_{r}^{0.23}}{\left(1-0.99 P_{r}\right)^{0.9}}\right] q^{0.8}$ \\
\hline Cooper $[32,33]$ & 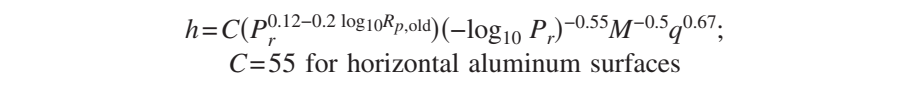 \\
\hline Gorenflo [34] & $\begin{array}{c}\frac{h}{h_{0}}=C F\left(P_{r}\right)\left(\frac{q}{q_{0}}\right)^{n} ; \quad C=\left(\frac{R_{a}}{R_{a 0}}\right)^{0.133} ; \quad R_{a 0}=0.4 \mu \mathrm{m} \\
F\left(P_{r}\right)=1.73 P_{r}^{0.27}+\left(6.1+\frac{0.68}{1-P_{r}}\right) P_{r}^{2} \text { and } n=0.9-0.3 P_{r}^{0.15} \text { for water } \\
F\left(P_{r}\right)=1.2 P_{r}^{0.27}+\left(2.5+\frac{1}{1-P_{r}}\right) P_{r} \text { and } n=0.9-0.3 P_{r}^{0.3} \text { for all other fluids }\end{array}$ \\
\hline Leiner $[58]$ & $\begin{array}{c}\frac{h}{P_{c} \sqrt{\mathfrak{\Re} / T_{c}}}=0.6161 C^{0.1512} K^{0.4894}\left[\frac{R_{a}}{\left(k_{B} T_{c} / P_{c}\right)^{1 / 3}}\right]^{0.133} F^{\prime}\left(P_{r}\right)\left(\frac{q}{P_{c} \sqrt{\mathfrak{R} T_{c}}}\right)^{n} \\
F^{\prime}\left(P_{r}\right)=43000^{n-0.75}\left[1.2 P_{r}^{0.27}+\left(2.5+\frac{1}{1-P_{r}}\right) P_{r}\right] ; n=0.9-0.3 P_{r}^{0.3} \\
C=\left.\frac{c_{p, l}}{\bar{R}}\right|_{P_{r}=0.1} ; \quad K=-\left.T_{r} \ln \left(\frac{P_{r}}{1-T_{r}}\right)\right|_{P_{r}=0.1}\end{array}$ \\
\hline Ribatski and Jabardo [45] & $h=C R_{a}^{0.2} P_{r}^{0.45}\left[-\log \left(P_{r}\right)\right]^{-0.8} M^{-0.5} q^{n}$ \\
\hline
\end{tabular}

$3 \%$ over the pressure $\left(0.08<P_{r}<0.9\right)$ and surface roughness $\left(0.22 \mu \mathrm{m}<R_{p, \text { old }}<4.31 \mu \mathrm{m}\right)$ ranges studied. It should be noted that $R_{p \text {,old }}$ used in the Cooper correlation is defined by DIN 4762/ 1:1960. Gorenflo [34] suggested the conversion $R_{a} \approx 0.4 R_{p \text {,old }}$, which is adopted in this work.

A comparison between the experimental data from the present work and predictions from the Cooper correlation is shown in Fig. 10. The Cooper correlation predicts heat transfer coefficients for FC-77 with mean absolute errors (MAEs) ranging from $12.9 \%$ for the roughest EDM surface to $33.4 \%$ for the polished surface with an overall MAE of $24.1 \%$. Here, the mean absolute error is defined as

$$
M A E=\frac{1}{N} \sum_{i=1}^{N} \frac{\left|h_{\mathrm{corr}, i}-h_{\mathrm{exp}, i}\right|}{h_{\mathrm{exp}, i}}
$$

where $i$ represents an experimental data point at a given heat flux.

For water under the given experimental conditions, the predictive capability of the Cooper correlation is poor, with MAEs ranging from $44.4 \%$ to $324 \%$ for the polished and roughest EDM surfaces, respectively. The poor predictions result from the reformulation of the roughness relationship of Nishikawa et al. At a fixed heat flux, the Cooper correlation predicts 13.6 times higher heat transfer coefficients on the roughest surface $(10.0 \mu \mathrm{m}) \mathrm{com}-$ pared with the smoothest $(0.038 \mu \mathrm{m})$, while the original relationship by Nishikawa et al. predicts a more modest increase by a factor of 3. Cooper did not consider such a low reduced pressure $\left(P_{r}=0.0046\right)$ as was used in the present study when reformulating the surface roughness relation of Nishikawa et al. At a reduced pressure of $P_{r}=0.064$ corresponding to the FC-77 experiments, Cooper's reformulation matches the relation of Nishikawa et al. within $20 \%$ over the surfaces studied. For this reason, the Cooper correlation is not recommended for reduced pressures much below $P_{r}=0.08$.

4.4 Gorenflo Correlation. The Gorenflo [34] correlation is shown in Table 3. Following Stephan's work [28], Gorenflo accounted for surface roughness using $h \propto R_{a}^{0.133}$. The Gorenflo correlation requires knowledge of a reference heat transfer coefficient, $h_{0}$, at a given reference heat flux, $q_{0}$. For water, a reference value of $h_{0}=5600 \mathrm{~W} / \mathrm{m}^{2} \mathrm{~K}$ at $q_{0}=20,000 \mathrm{~W} / \mathrm{m}^{2}$ was obtained from the VDI Heat Atlas [34]. For fluids for which no suitable experimental data are available, such as FC-77, Gorenflo recommended using the Stephan and Preußer correlation (as cited in Ref. [34]), although greater uncertainties can be expected in the following prediction. 

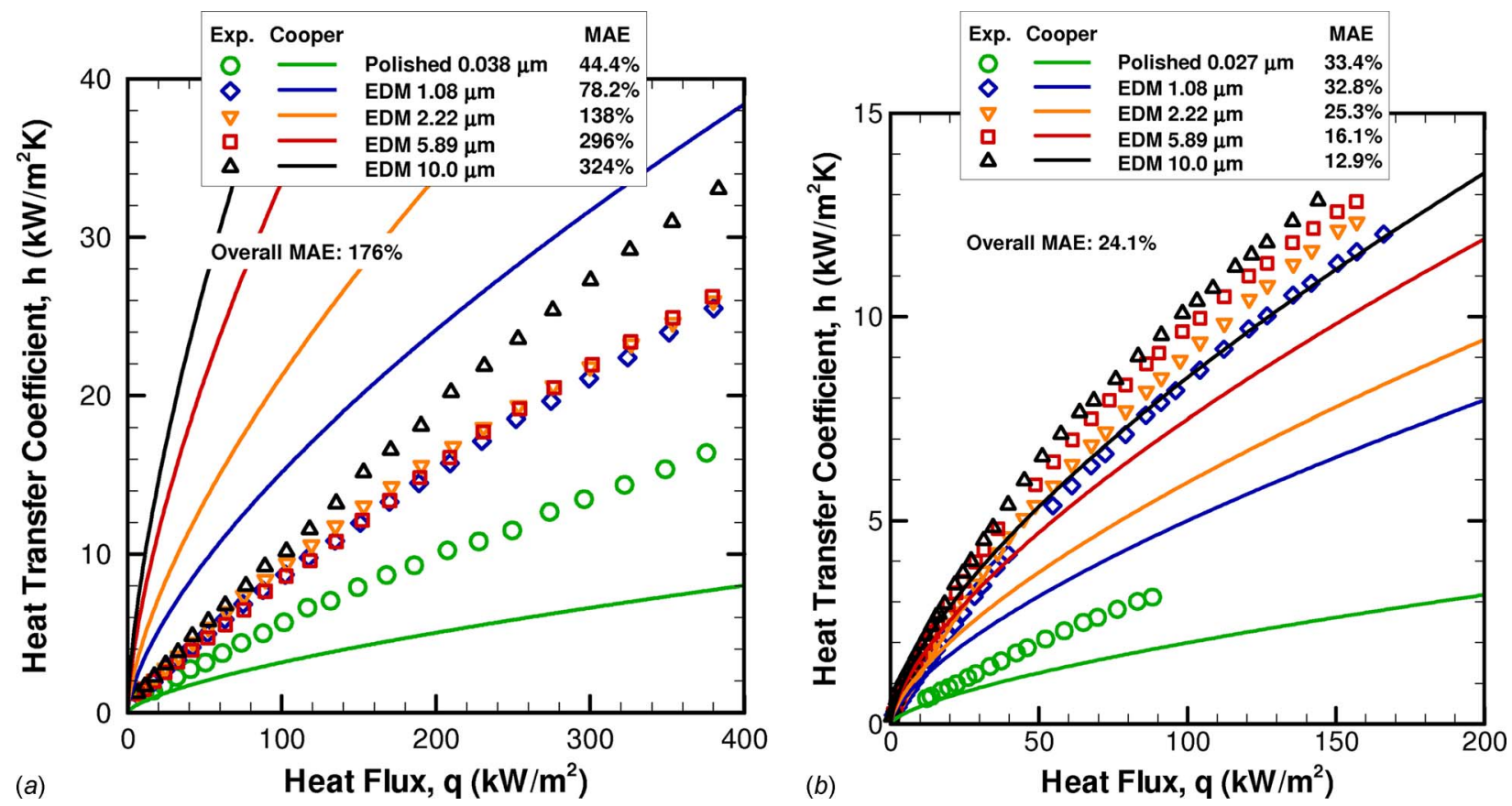

Fig. 10 Comparison between experimental data and predictions from the Cooper correlation $[32,33]$ for (a) water and (b) FC-77

$$
\begin{aligned}
\frac{h d_{0}}{k_{l}}= & 0.1\left(\frac{q_{0} d_{0}}{k_{l} T_{\mathrm{sat}}}\right)^{0.674}\left(\frac{\rho_{v}}{\rho_{l}}\right)^{0.156}\left(\frac{h_{f g} d_{0}^{2}}{\alpha_{l}^{2}}\right)^{0.371}\left(\frac{\alpha_{l}^{2} \rho_{l}}{\sigma d_{0}}\right)^{0.350} \\
& \times\left(\frac{\mu_{l} c_{p, l}}{k_{l}}\right)^{-0.16}
\end{aligned}
$$

(3) Gorenflo suggested evaluating $h$ using fluid properties at a pressure $P_{r}=0.03$ and then converting to $h_{0}$ at the reference pressure of $P_{r 0}=0.1$ through the use of the $F\left(P_{r}\right)$ equation shown in Table
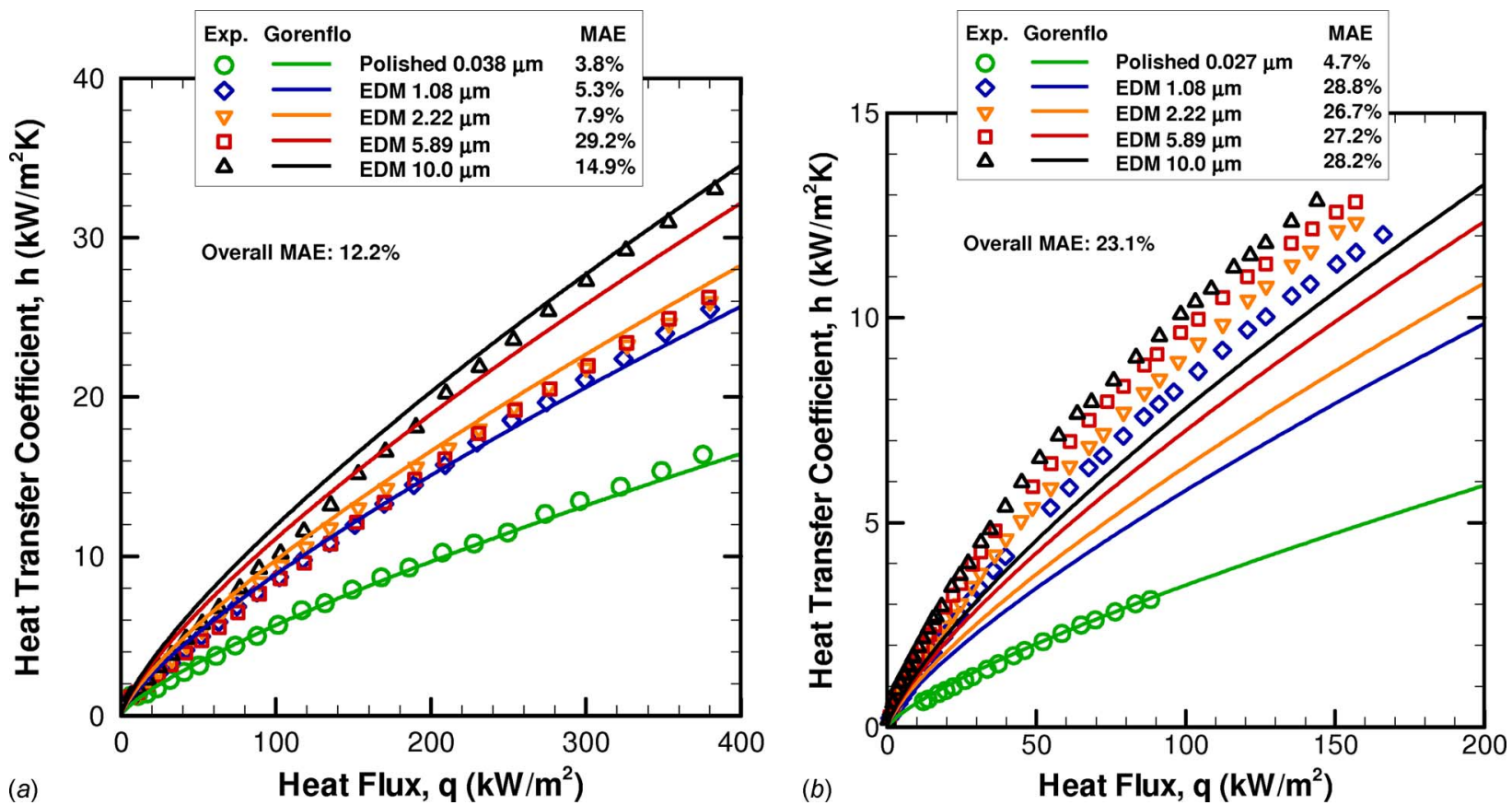

Fig. 11 Comparison between experimental data and predictions from the Gorenflo correlation [34] for (a) water and (b) FC-77 

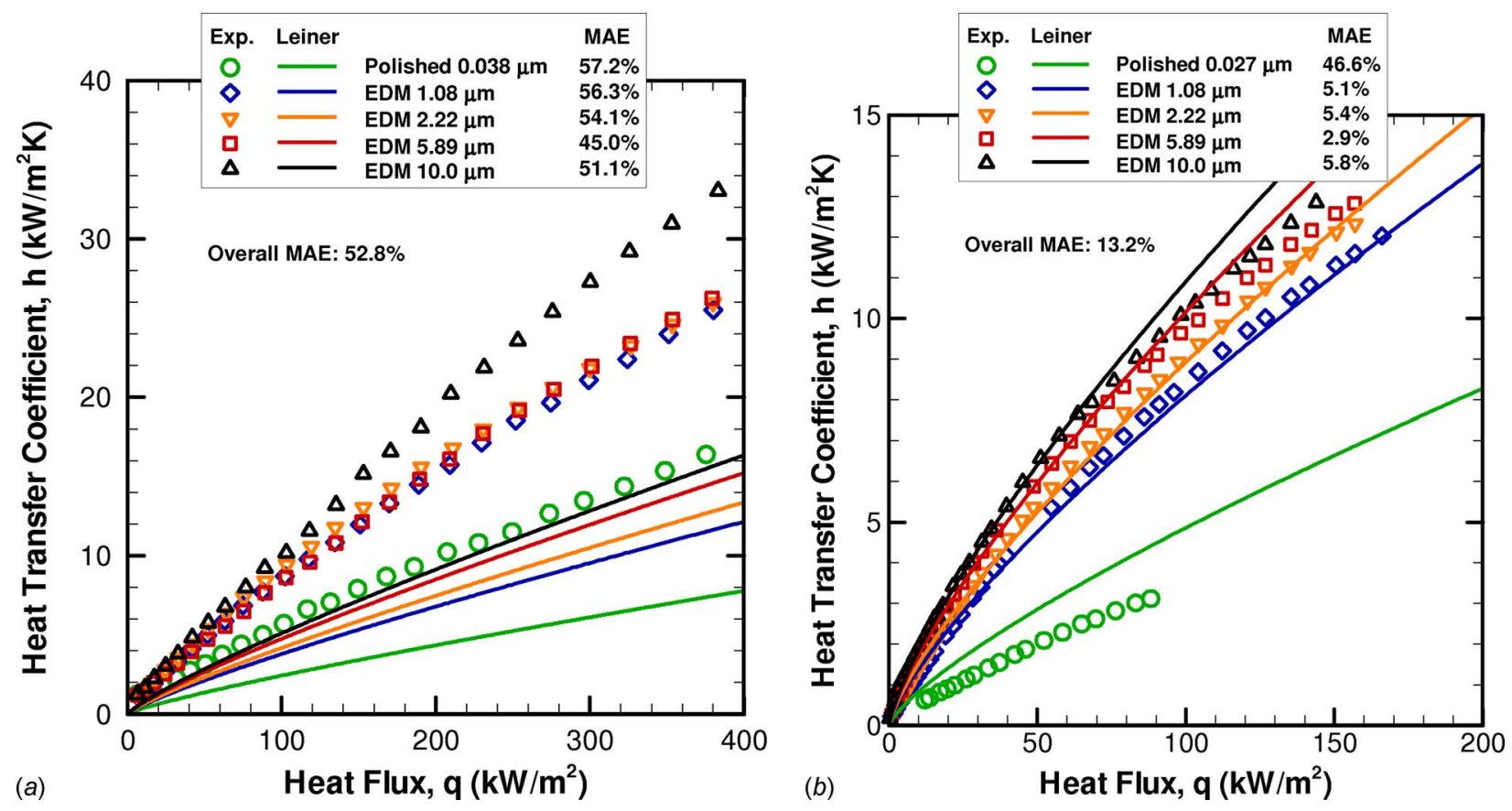

Fig. 12 Comparison between experimental data and predictions from the Leiner correlation [59] for (a) water and (b) FC-77

3. For FC-77, the estimated reference heat transfer coefficient is $h_{0}=1840 \mathrm{~W} / \mathrm{m}^{2} \mathrm{~K}$ at $q_{0}=20,000 \mathrm{~W} / \mathrm{m}^{2}$.

A comparison between the Gorenflo correlation and the experimental results for water and FC-77 is shown in Fig. 11. The Gorenflo correlation predicts the experimental results in water quite well, with a MAE of only $3.8 \%$ for the polished surface and an overall MAE of $12.2 \%$. For FC-77, the predictions are less accurate, particularly for the EDM surface with MAEs in the range of 26-29\%, although the predictions for the polished surface are quite good with a MAE of $4.7 \%$.

4.5 Leiner Correlation. The reliance on reference values reduces the utility of the Gorenflo correlation as reference values are only available for a limited number of fluids. Leiner [56] addressed this issue by using the principles of thermodynamic similarity to further develop the Gorenflo correlation by removing the need for reference values (see Table 3 ). It should be noted that the pressure function, $F^{\prime}\left(P_{r}\right)$, was specifically developed for fluids other than water, and so the Leiner correlation is not expected to offer accurate predictions of boiling in water. In this case, the Gorenflo correlation should provide better predictions.

The comparison between the Leiner correlation and experimental results is shown in Fig. 12. As expected, the Leiner correlation is not particularly accurate for water, with MAEs of approximately 50\%. The Leiner correlation fares much better with FC-77 with MAEs around 5\% for the EDM surfaces, but the correlation significantly overpredicts heat transfer coefficients for the polished surface with a MAE of $46.6 \%$. Although the Leiner correlation has a lower overall MAE than the Gorenfo correlation for FC-77 (13.2\% versus $23.1 \%)$, this is probably influenced by the fact that four EDM surfaces (where the Leiner correlation provides the best predictions) and only one polished surfaces (where the Gorenflo provides the best predictions) were considered in the present work. Thus, despite the lower overall MAE of the Leiner correlation, it is inconclusive whether much additional accuracy is provided by the Leiner correlation over the Gorenflo correlation for FC-77.

The main problem with the Gorenflo and Leiner correlations' predictions for FC-77 is that neither accurately accounts for the influence of surface roughness. Both correlations use Stephan's recommendation of $m=0.133$, which is closer to the $m=0.1$ found for water in this study, but differs from the $m=0.2$ found for FC-77. If the Gorenflo correlation in Table 3 is modified so that factor $C$ becomes

$$
C=\left(\frac{R_{a}}{R_{a 0}}\right)^{0.2}
$$

then the overall MAE for FC-77 is reduced from $23.1 \%$ to $15.8 \%$. If a reference heat transfer coefficient $h_{0}=2160 \mathrm{~W} / \mathrm{m}^{2} \mathrm{~K}$ at $q_{0}$ $=20,000 \mathrm{~W} / \mathrm{m}^{2}$, which more closely matches the experimental results, is used instead of $h_{0}=1840 \mathrm{~W} / \mathrm{m}^{2} \mathrm{~K}$ as estimated by the Stephan and Preußer correlation [34], the MAE is further reduced to $6.7 \%$. Modifying the Leiner correlation to account for a surface roughness exponent $m=0.2$ requires more manipulation, but it can be shown that

$$
\begin{aligned}
\frac{h}{P_{c} \sqrt{\bar{\Re} / T_{c}}}= & 0.6161 C^{0.1512} K^{0.4894} F^{\prime}\left(P_{r}\right) \\
& \times\left(\frac{q}{P_{c} \sqrt{\bar{\Re} T_{c}}}\right)^{n}\left\{\frac{R_{a}^{0.2}}{R_{a 0}^{0.067}\left[\left(k_{B} T_{c} / P_{c}\right)^{1 / 3}\right]^{0.133}}\right\}
\end{aligned}
$$

The overall MAE for FC-77 increases from $13.2 \%$ to $18.2 \%$ when using Eq. (6) instead of the original Leiner correlation, although the predictions are notably improved for the polished surface, with an MAE of $21.1 \%$.

For water, the Gorenflo correlation clearly provides the best predictive capabilities. From the discussion above, the modified Gorenflo correlation provided the lowest errors for FC-77. However, given the limited number of surfaces tested, and considering the wide range of conclusions from other researchers regarding the influence of roughness on nucleate boiling, it is unclear whether a modification to the Gorenflo correlation for FC-77 will lead to a general improvement in accuracy. Further, it is unclear whether any general improvement in predictive capability can be achieved when using standard surface roughness parameters to account for the effects of surface characteristics on boiling heat transfer. Although it has been proposed that the relationship $h$ $\propto R^{m}$ where $m=f(\theta)$ may lead to an improvement in predictions, more experimental data are needed to conclusively establish this dependence. Moreover, the current experimental data indicate 
general weaknesses in using $h \propto R^{m}$ to account for surface roughness, and it is therefore recommended that future research focus on developing new methods of characterizing boiling surfaces.

\section{Conclusions}

Pool boiling at atmospheric pressure from surfaces with a wide range of surface roughness in two fluids with differing wetting characteristics was experimentally explored. For water, the results indicate little improvement in heat transfer coefficient for roughness beyond $R_{a}=1.08 \mu \mathrm{m}$, except for a very rough $10.0 \mu \mathrm{m}$ surface, which had significantly higher heat transfer coefficients. On the same set of surfaces, FC-77 exhibited a different trend with continuously increasing heat transfer coefficient with respect to surface roughness, at a fixed heat flux. The general trend of increasing heat transfer coefficient with surface roughness was correlated using $h \propto R^{m}$. The results indicate a stronger dependence on surface roughness for FC-77 with $m=0.2$ compared with $m$ $=0.1$ for water.

The experimental results were compared with predictions from widely used nucleate boiling correlations. Due to differences in the surface roughness exponent for the two fluids, no single correlation provides entirely satisfactory predictions. The Gorenflo correlation provided the lowest errors for water. For FC-77, the lowest errors were obtained using a modified Gorenflo correlation with a surface roughness exponent of $m=0.2$. Due to the numerous deficiencies associated with correlating nucleate boiling data using surface roughness parameters, it is recommended that future research focus on developing new techniques for characterizing boiling surfaces.

\section{Acknowledgment}

Dr. Dong Liu, Dr. Tailian Chen, Dr. Poh-Seng Lee, and Dr. Stefan Bertsch are thanked for their helpful and insightful discussions. Funding from the Indiana 21st Century Research and Technology Fund, and the Cooling Technologies Research Center, an NSF IUCRC at Purdue University, is gratefully acknowledged.

\section{Nomenclature}

$$
\begin{aligned}
a, b, C, K & =\text { empirical constants } \\
c_{p} & =\text { specific heat } \\
d_{0} & =\text { bubble departure diameter } \\
F, F^{\prime} & =\text { pressure functions } \\
f & =\text { bubble emission frequency } \\
g & =\text { acceleration due to gravity } \\
h & =\text { heat transfer coefficient } \\
h_{f g} & =\text { heat of vaporization } \\
k & =\text { thermal conductivity } \\
k_{\mathrm{B}} & =\text { Boltzmann constant, } k_{\mathrm{B}}=1.3807 \times 10^{-23} \mathrm{~J} / \mathrm{K} \\
M & =\text { molecular weight } \\
m & =\text { surface roughness exponent } \\
N & =\text { active nucleation site density } \\
n & =\text { heat flux exponent } \\
P & =\text { pressure } \\
\Delta P & =\text { excess pressure corresponding to wall super- } \\
& \text { heat, } \Delta P=P_{w}-P_{\text {sat }} \\
\operatorname{Pr} & =\text { Prandtl number, Pr }=c_{p} \mu / k \\
\mathfrak{R} & =\text { universal gas constant, } \mathfrak{R}=8.314 \mathrm{~kJ} / \mathrm{K} \mathrm{kmol} \\
\mathfrak{R} & =\text { specific gas constant, } \bar{\Re}=\mathfrak{R} / M \\
R_{q}, & =\text { roughness parameters according to ASME } \\
R_{z} & \text { B46.1-1995 } \\
R_{p, \text { old }} & =\text { "Glättungstiefe" according to DIN } 4762 / 1: 1960 \\
q & =\text { heat flux } \\
T & =\text { temperature } \\
\Delta T & =\text { wall superheat, } \Delta T=T_{w}-T_{\text {sat }}
\end{aligned}
$$

Greek

$$
\alpha=\text { thermal diffusivity, } \alpha=k / \rho c_{p}
$$

$$
\begin{aligned}
\theta & =\text { contact angle } \\
\mu & =\text { dynamic viscosity } \\
\rho & =\text { density } \\
\sigma & =\text { surface tension }
\end{aligned}
$$

Subscripts

$$
\begin{aligned}
c & =\text { critical } \\
\text { corr } & =\text { correlation } \\
\exp & =\text { experiment } \\
l & =\text { liquid } \\
r & =\text { reduced } \\
\text { sat } & =\text { saturation } \\
v & =\text { vapor } \\
w & =\text { wall } \\
0 & =\text { reference }
\end{aligned}
$$

\section{References}

[1] Jakob, M., 1936, "Heat Transfer in Evaporation and Condensation-I," Mech. Eng. (Am. Soc. Mech. Eng.), 58, pp. 643-660.

[2] Westwater, J. W., 1958, "Boiling Heat Transfer," Am. Sci., 47, pp. 427-446.

[3] Clark, H. B., Strenge, P. S., and Westwater, J. W., 1959, "Active Sites for Nucleate Boiling," Chem. Eng. Prog., Symp. Ser., 55(29), pp. 103-110.

[4] Bankoff, S. G., 1958, "Ebullition From Solid Surfaces in the Absence of a Pre-Existing Gaseous Phase," Trans. ASME, 79, pp. 735-740.

[5] Bankoff, S. G., 1958, "Entrapment of Gas in the Spreading of a Liquid Over a Rough Surface," AIChE J., 4(1), pp. 24-26.

[6] Griffith, P., and Wallis, J. D., 1960, "The Role of Surface Conditions in Nucleate Boiling," Chem. Eng. Prog., Symp. Ser., 56(30), pp. 49-63.

[7] Hsu, Y. Y., 1962, "On the Size Range of Active Nucleation Cavities on Heating Surface," ASME J. Heat Transfer, 84, pp. 207-216.

[8] Corty, C., and Foust, A. S., 1955, "Surface Variables in Nucleate Boiling," Chem. Eng. Prog., Symp. Ser., 51(17), pp. 1-12.

[9] Kurihara, H. M., and Myers, J. E., 1960, "The Effects of Superheat and Surface Roughness on Boiling Coefficients," AIChE J., 6(1), pp. 83-91.

[10] Hsu, S. T., and Schmidt, F. W., 1961, "Measured Variations in Local Surface Temperatures in Pool Boiling of Water," ASME J. Heat Transfer, 83, pp. 254-260.

[11] Marto, P. J., and Rohsenow, W. M., 1966, "Effects of Surface Conditions on Nucleate Pool Boiling of Sodium," ASME J. Heat Transfer, 88, pp. 196-204.

[12] Berenson, P. J., 1962, "Experiments on Pool-Boiling Heat Transfer," Int. J. Heat Mass Transfer, 5, pp. 985-999.

[13] Webb, R. L., 1981, "The Evolution of Enhanced Surface Geometries for Nucleate Boiling," Heat Transfer Eng., 2, pp. 46-69.

[14] Webb, R. L., 2004, "Odyssey of the Enhanced Boiling Surface," ASME J. Heat Transfer, 126, pp. 1051-1059.

[15] Bier, K., Gorenflo, D., Salam, M., and Tanes, Y., 1978, "Pool Boiling Heat Transfer and Size of Active Nucleation Centers for Horizontal Plates With Different Surface Roughness," Proceedings of the Sixth International Heat Transfer Conference, Toronto, Canada, Vol. 1, pp. 151-156.

[16] Chowdhury, S. K. R., and Winterton, R. H. S., 1985, "Surface Effects in Pool Boiling," Int. J. Heat Mass Transfer, 28(10), pp. 1881-1889.

[17] Vachon, R. I., Tanger, G. E., Davis, D. L., and Nix, G. H., 1968, "Pool Boiling on Polished and Chemically Etched Stainless-Steel Surfaces," ASME J. Heat Transfer, 80, pp. 231-238.

[18] Kravchenko, V. A., and Ostrovskiy, Yu. N., 1979, "Effect of Surface Roughness on Boiling Heat Transfer to Light Hydrocarbons and Nitrogen," Heat Transfer-Sov. Res., 11(1), pp. 133-137.

[19] Grigoriev, V. A., Pavlov, Yu. M., and Ametistov, Ye. V., 1974, "An Investigation of Nucleate Boiling Heat Transfer of Helium," Proceedings of the Fifth International Heat Transfer Conference, Tokyo, Japan, pp. 45-49.

[20] Yang, S. R., and Kim, R. H., 1988, "A Mathematical Model of the Pool Boiling Nucleation Site Density in Terms of the Surface Characteristics," Int. J. Heat Mass Transfer, 31(6), pp. 1127-1135.

[21] Cornwell, K., 1977, "Naturally Formed Boiling Site Cavities," Lett. Heat Mass Transfer, 4, pp. 63-72.

[22] Shoukri, M., and Judd, R. L., 1975, "Nucleation Site Activation in Saturated Boiling," ASME J. Heat Transfer, 97, pp. 93-98.

[23] Wang, C. H., and Dhir, V. K., 1993, "Effect of Surface Wettability on Active Nucleation Site Density During Pool Boiling of Water on a Vertical Surface," ASME J. Heat Transfer, 115, pp. 659-669.

[24] Wang, C. H., and Dhir, V. K., 1993, "On the Gas Entrapment and Nucleation Site Density During Pool Boiling of Saturated Water," ASME J. Heat Transfer, 115, pp. 670-679.

[25] Qi, Y., Klausner, J. F., and Mei, R., 2004, "Role of Surface Structure in Heterogeneous Nucleation," Int. J. Heat Mass Transfer, 47, pp. 3097-3107.

[26] Luke, A., 2004, "Active and Potential Bubble Nucleation Sites on Different Structured Heated Surfaces," Chem. Eng. Res. Des., 82, pp. 462-470.

[27] Luke, A., 2006, "Preparation, Measurement and Analysis of Microstructure of Evaporator Surfaces," Int. J. Therm. Sci., 45, pp. 237-256

[28] Stephan, K., 1963, "Mechanismus und Modellgesetz des Wärmeübergangs bei der Blasenverdampfung," Chem.-Ing.-Tech., 35(11), pp. 775-784.

[29] Danilova, G. N., and Bel'skii, V. K., 1965, "Study of Heat Transfer on Boiling 
of Freon 113 and Freon 12 on Pipes of Differing Roughness," Kholodil'naia Tekhnika, 4, pp. 24-28.

[30] Nishikawa, K., Fujita, Y., Ohta, H., and Hidaka, S., 1982, "Effect of the Surface Roughness on the Nucleate Boiling Heat Transfer Over the Wide Range of Pressure," Proceedings of the Seventh International Heat Transfer Conference, München, Germany, Vol. 4, pp. 61-66.

[31] Nishikawa, K., Fujita, Y., Ohta, H., and Hidaka, S., 1982, "Effects of System Pressure and Surface Roughness on Nucleate Boiling Heat Transfer," Memoirs of the Faculty of Engineering, Kyushu University, 42(2), pp. 95-111.

[32] Cooper, M. G., 1984, "Saturation Nucleate Pool Boiling-A Simple Correlation," First UK National Conference on Heat Transfer, University of Leeds, pp. 785-793.

[33] Cooper, M. G., 1984, "Heat Flow Rates in Saturated Nucleate Pool Boiling-A Wide-Ranging Examination Using Reduced Properties," Adv. Heat Transfer, 16, pp. 157-239.

[34] Gorenflo, D., 1993, "Pool Boiling," VDI Heat Atlas, VDI Verlag, Düsseldorf.

[35] 3M Corporation, 1986, Fluorinert Liquids Product Manual, Industrial Chemical Products Division.

[36] 3M Corporation, 2000, Fluorinert Electronic Liquid FC-77 Product Information No. 98-0212-2309-8 (HB), Specialty Materials Division.

[37] Raben, I. A., Beaubouef, R. T., and Commerford, G. E., 1965, "A Study of Heat Transfer in Nucleate Pool Boiling of Water at Low Pressure," Chem. Eng. Prog., Symp. Ser., 61(57), pp. 249-257.

[38] Anderson, T. M., and Mudawar, I., 1989, "Microelectronic Cooling by Enhanced Pool Boiling of a Dielectric Fluorocarbon Liquid," ASME J. Heat Transfer, 111, pp. 752-759.

[39] Baldwin, C. S., Bhavnani, S. H., and Jaeger, R. C., 2000, "Toward Optimizing Enhanced Surfaces for Passive Immersion Cooled Heat Sinks," IEEE Trans. Compon. Packag. Tech., 23(1), pp. 70-79.

[40] Parker, J. L., and El-Genk, M. S., 2005, "Enhanced Saturation and Subcooled Boiling of FC-72 Dielectric Liquid," Int. J. Heat Mass Transfer, 48, pp. 37363752.

[41] Bhavnani, S. H., Tsai, C.-P., Jaegar, R. C., and Eison, D. L., 1993, “An Integral Heat Sink for Cooling Microelectronic Components," ASME J. Electron. Packag., 115, pp. 284-291.

[42] Bergles, A. E., and Chyu, M. C., 1982, "Characteristics of Nucleate Pool Boiling From Porous Metallic Coatings," ASME J. Heat Transfer, 104, pp. 279-285.

[43] Hatton, A. P., and Hall, I. S., 1966, "Photographic Study of Boiling on Prepared Surfaces," Proceedings of the Third International Heat Transfer Conference, Chicago, IL, Vol. 4, pp. 24-37.
[44] Fedders, H., 1971, "Messung des Wärmeüberganges beim Blasensieden von Wasser an metallischen Rohren," Kernforschungsanlage Jülich Report No. Jül740-RB.

[45] Ribatski, G., and Jabardo, J. M. S., 2003, "Experimental Study of Nucleate Boiling of Halocarbon Refrigerants on Cylindrical Surfaces," Int. J. Heat Mass Transfer, 46, pp. 4439-4451.

[46] Chun, M.-H., and Kang, M.-G., 1998, "Effects of Heat Exchanger Tube Parameters on Nucleate Pool Boiling Heat Transfer," ASME J. Heat Transfer, 120(2), pp. 468-476.

[47] Vachon, R. I., Tanger, G. E., Nix, G. H., and Davis, D. L., 1965, "Pool Boiling of Water From Mechanically Polished and Chemically Etched Stainless Steel Surfaces," Auburn Research Foundation Report No. IV.

[48] Vachon, R. I., Tanger, G. E., Nix, G. H., and Goree, L. H., 1966, "Pool Boiling of Water on 304 Stainless Steel Etched With Hydrochloric Acid," Auburn Research Foundation Report No. VI.

[49] Kurihara, H. M., 1956, "Fundamental Factors Affecting Boiling Coefficients," Ph.D. thesis, Purdue University, Lafayette, IN.

[50] Forster, H. K., and Zuber, N., 1955, "Dynamics of Vapor Bubbles and Boiling Heat Transfer," AIChE J., 1(4), pp. 531-535.

[51] Rohsenow, W. M., 1952, "A Method of Correlating Heat-Transfer Data for Surface Boiling of Liquids," Trans. ASME, 74, pp. 969-976.

[52] Vachon, R. I., Nix, G. H., and Tanger, G. E., 1968, "Evaluation of Constants for the Rohsenow Pool-Boiling Correlation," ASME J. Heat Transfer, 90, pp 239-247.

[53] Pioro, I. L., 1999, "Experimental Evaluation of Constants for the Rohsenow Pool Boiling Correlation,” Int. J. Heat Mass Transfer, 42, pp. 2003-2013.

[54] Tien, C. L., 1962, “A Hydrodynamic Model for Nucleate Pool Boiling," Int. J. Heat Mass Transfer, 5, pp. 533-540.

[55] Lienhard, J. H., 1963, "A Semi-Rational Nucleate Boiling Heat Flux Correlation," Int. J. Heat Mass Transfer, 6, pp. 215-219.

[56] Mikic, B. B., and Rohsenow, W. M., 1969, "A New Correlation of PoolBoiling Data Including the Effect of Heating Surface Characteristics," ASME J. Heat Transfer, 91, pp. 245-250.

[57] Danilova, G. N., 1970, "Correlation of Boiling Heat Transfer Data for Freons," Heat Transfer-Sov. Res., 2(2), pp. 73-78.

[58] Leiner, W., 1994, "Heat Transfer by Nucleate Pool Boiling-General Correlation Based on Thermodynamic Similarity," Int. J. Heat Mass Transfer, 37(5), pp. 763-769.

[59] Cooper, M. G., 1982, "Correlations for Nucleate Boiling-Formulation Using Reduced Properties," PCH, PhysicoChem. Hydrodyn., 3(2), pp. 89-111. 